Project 09-836

\title{
Rapid Automated Dissolution and Analysis Techniques for Radionuclides in Recycle Process
} Streams

\section{Integrated University Programs}

Dr. Ralf Sudowe

University of Nevada, Las Vegas

Terry Todd, Technical POC

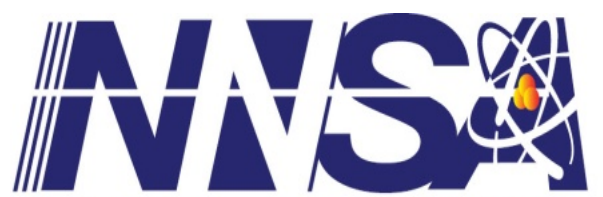




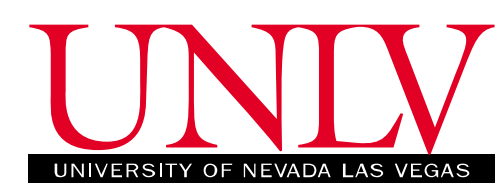

\title{
Rapid Automated Dissolution and Analysis Techniques for Radionuclides in Recycle Process Streams
}

\author{
Project Duration: 10/08/2009 - 9/30/2012 \\ Final Technical Report
}

Issued: January 2012

Audrey Roman ${ }^{1}$, Ashlee Dailey ${ }^{1}$, Elaine Go $^{1}$ and Ralf Sudowe ${ }^{1,2}$

\author{
${ }^{1}$ Radiochemistry Program \\ ${ }^{2}$ Department of Health Physics \\ University of Nevada, Las Vegas \\ Las Vegas, Nevada 89154
}

Prepared for the Unite States Department of Energy

Nuclear Energy University Programs

Award Number DE-AC07-05ID-14517 - Subcontract 00091998 


\section{Table of Contents}

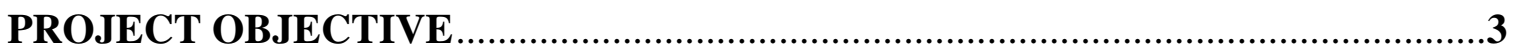

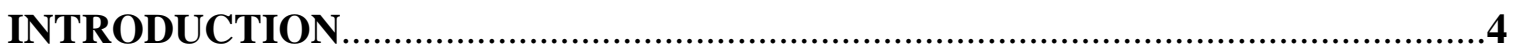

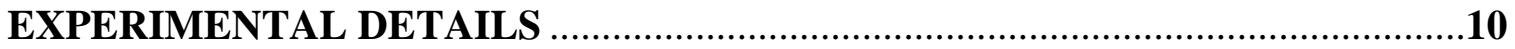

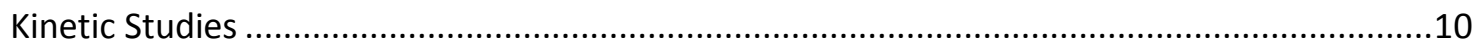

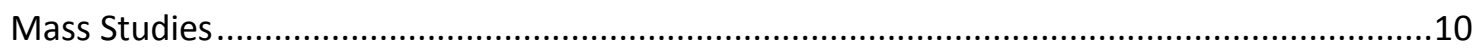

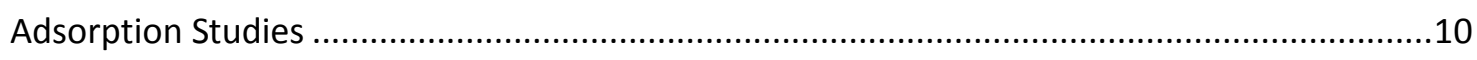

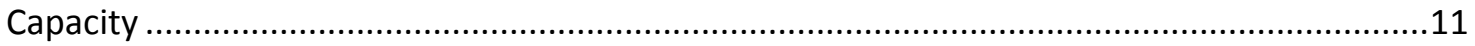

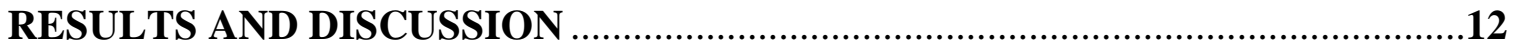

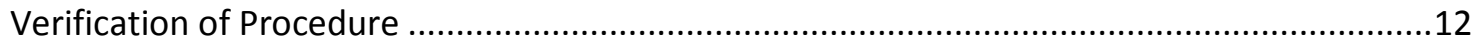

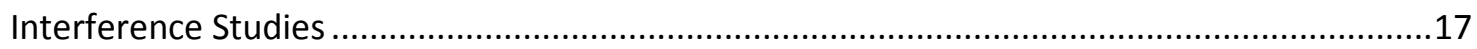

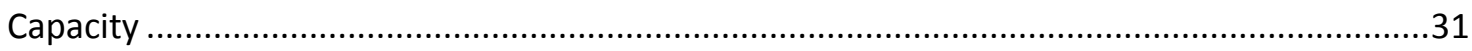

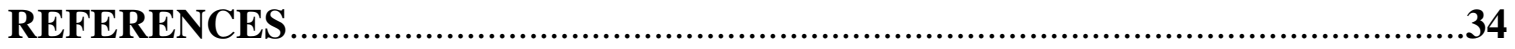




\section{PROJECT OBJECTIVE}

The analysis of process samples for radionuclide content is an important part of current procedures for material balance and accountancy in the different process streams of a recycling plant. The destructive sample analysis techniques currently available necessitate a significant amount of time. It is therefore desirable to develop new sample analysis procedures that allow for a quick turnaround time and increased sample throughput with a minimum of deviation between samples. In particular new capabilities for rapid sample dissolution and radiochemical separation are required. Most of the radioanalytical techniques currently employed for sample analysis are based on manual laboratory procedures. Such procedures are time and labor intensive and not well suited for situations in which a rapid sample analysis is requires and/or a large number of samples needed to be analyzed.

To address this issue we are currently investigating radiochemical separation methods based on extraction chromatography that have been specifically optimized for the analysis of process stream samples. The influence of potential interferences present in the process samples as well as mass loading, flow rate and resin performance is being studied. In addition the potential to automate these procedures utilizing a robotic

platform is evaluated. Initial studies have been carried out using the commercially available DGA resin. This resin shows an affinity for $\mathrm{Am}, \mathrm{Pu}, \mathrm{U}$, and Th and is also exhibiting signs of a possible synergistic effects in the presence of iron. [1] 


\section{INTRODUCTION}

Even though it is known that DGA resin has a high affinity for $\mathrm{Am}, \mathrm{Cm}$, and $\mathrm{Pu}$ in nitric and hydrochloric acid, as seen below, further studies are needed since the dissolved fuel and raffinate will have much more complex compositions than what has been previously studied. The more complex composition has the potential to deviate the sorption of Am, Cm and Pu from normal sorption characteristics. For this reason, further characterization of DGA resin in regards to the composition of spent fuel is essential for understanding how DGA should be used for separating $\mathrm{Am}, \mathrm{Cm}$, and Pu from the rest of the radionuclides.
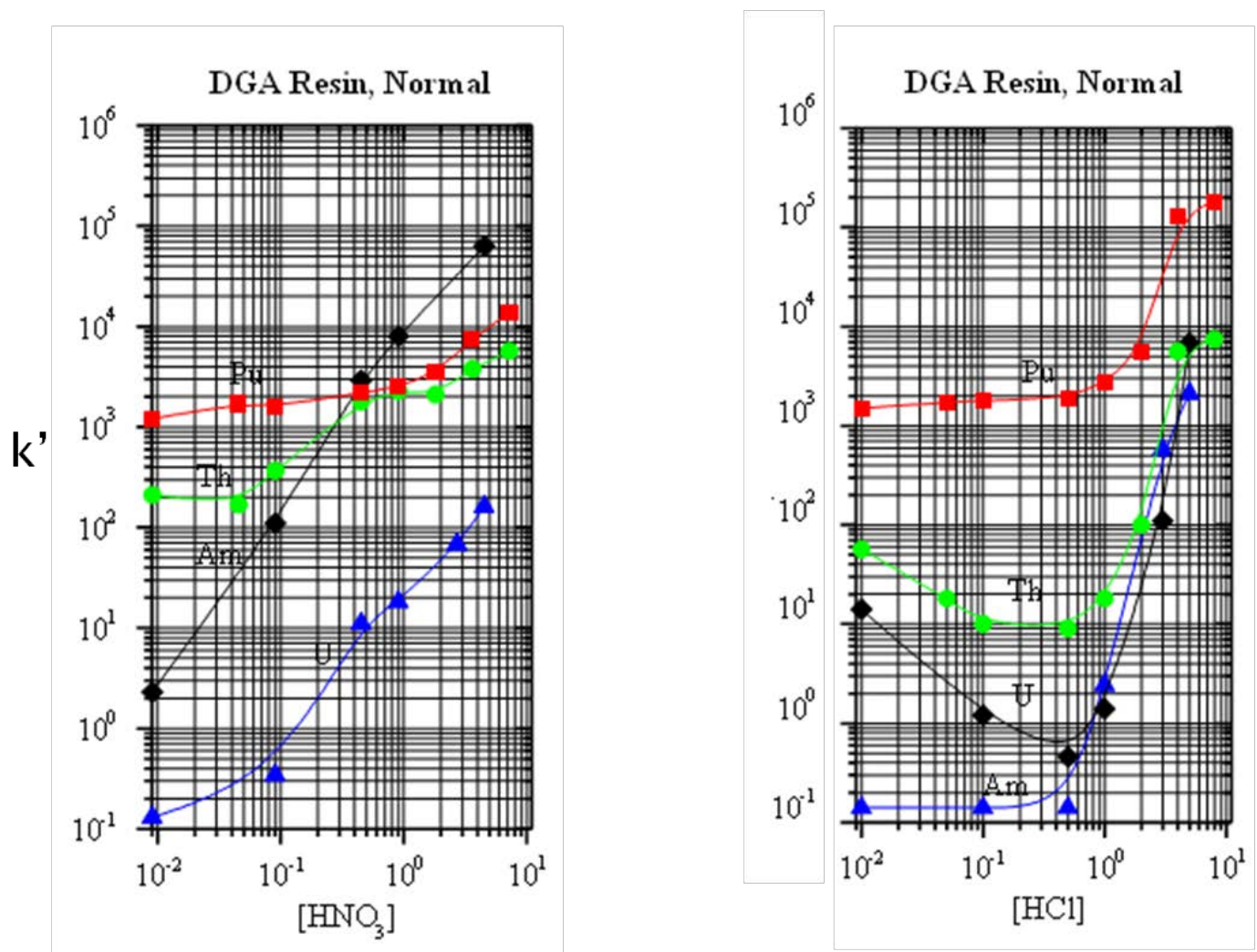

Figure $1 \mathrm{Am}$ and $\mathrm{Pu}$ Sorption in $\mathrm{HNO}_{3}$ and $\mathrm{HCl}$

The sorption of 60 elements has been investigated for DGA in varying nitric and hydrochloric acid, as seen in Figure 2 and 3 below. Therefore very little sorption studies on pure elements were necessary for this project; although, in literature, sorption characteristics have yet to be reported for Technetium. Due to the fact that Tc is a large 
Rapid Automated Dissolution and Analysis Techniques for Radionuclides in Recycle Process Streams

constituent of dissolved fuel its adsorption behavior was also investigated as part of this project.

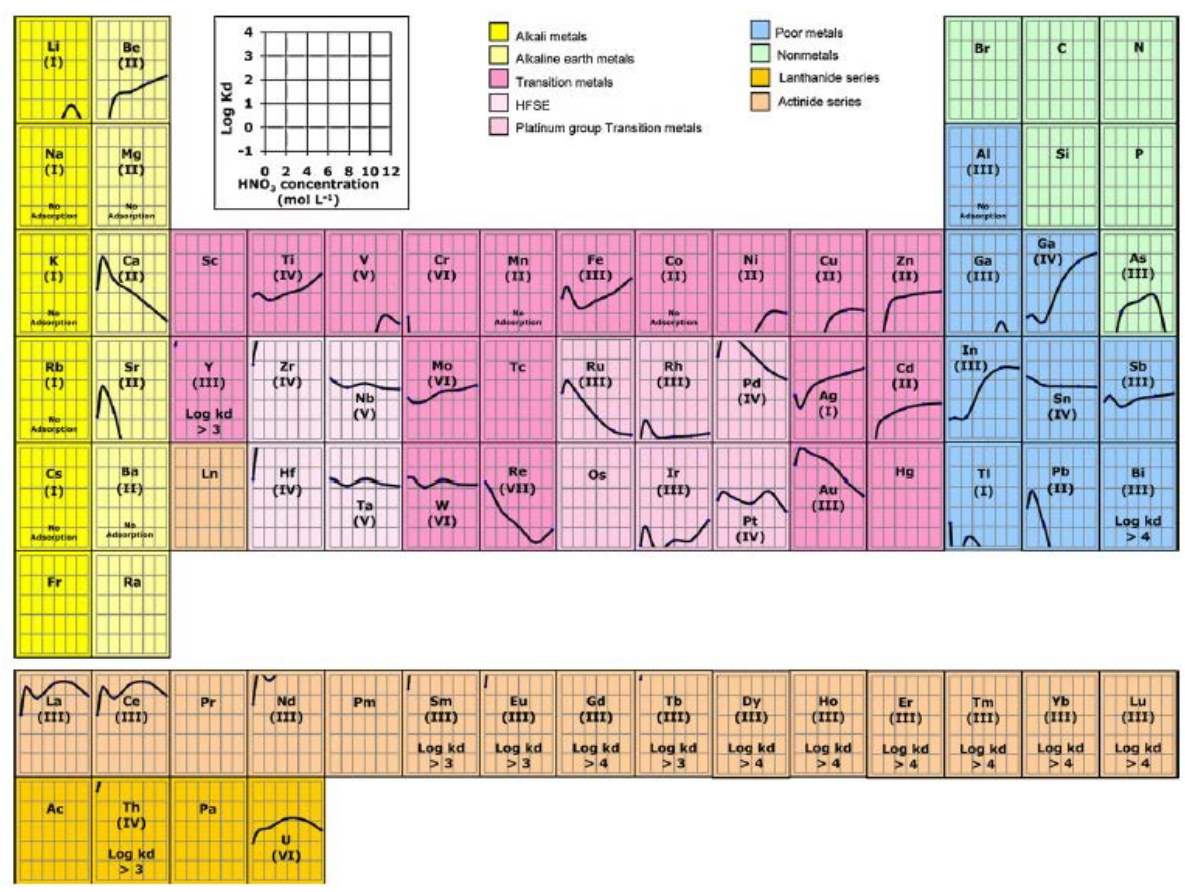

Figure 2 Sorption Studies in Varying $\mathrm{HNO}_{3}$ Concentrations [2]

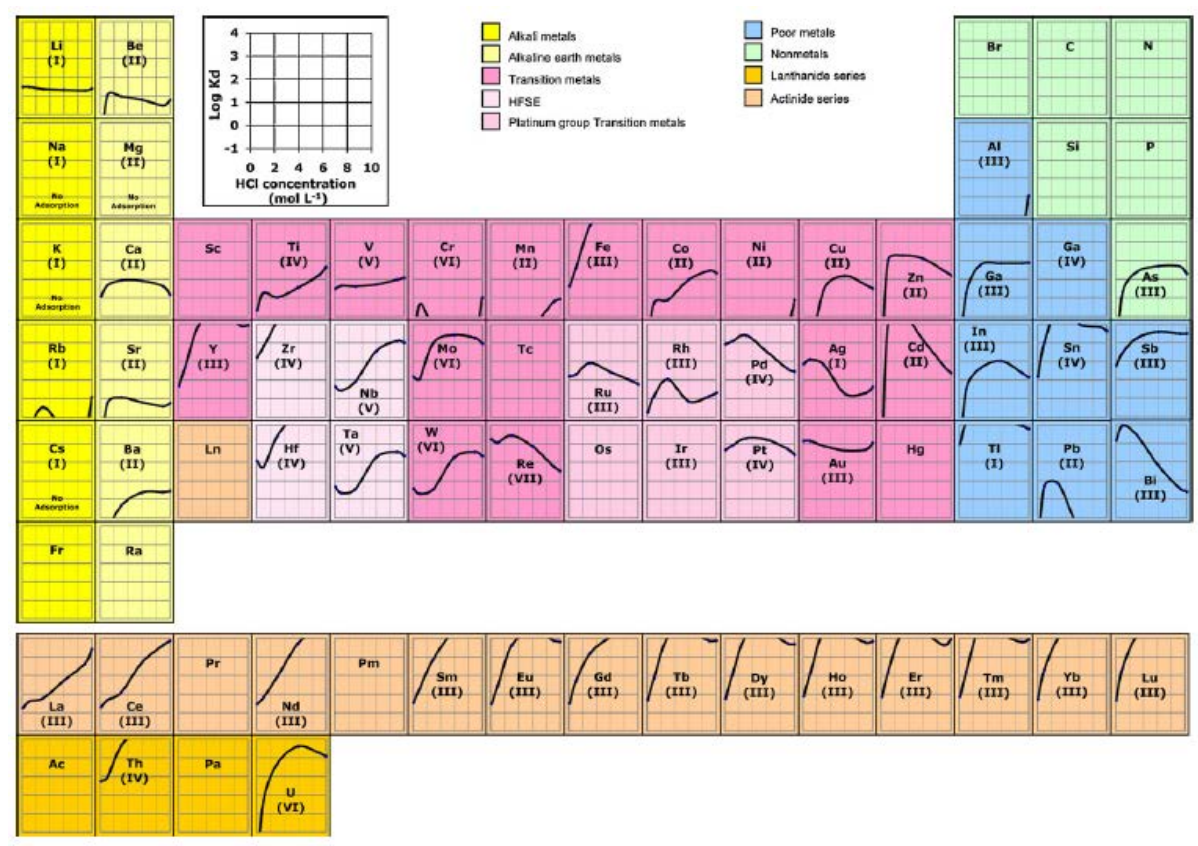

Figure 3 Sorption Studies for Varying HCl Concentrations [2] 
Even though most of the sorption studies have been performed for the appropriate acids of interest, the interference and synergistic effects of each element has not been studied. Hence, the majority of the work for this project revolved around these effect id competing cations and ions on the adsorption behavior of the elements of interest. An example of the effects a metal can have on the actinides is shown below, in Figure 4. Horwitz found an enhancement of Am extraction for the first chloride complex of ferric iron. It was determined that other trivalent metal ions would possess similar characteristics. Upon studying Fe(III) affects on $\mathrm{Pu}(\mathrm{IV})$, it was found that in the presence of Fe(III) the uptake of Pu(IV) was suppressed, as seen below as seen in Figure 5. [3]
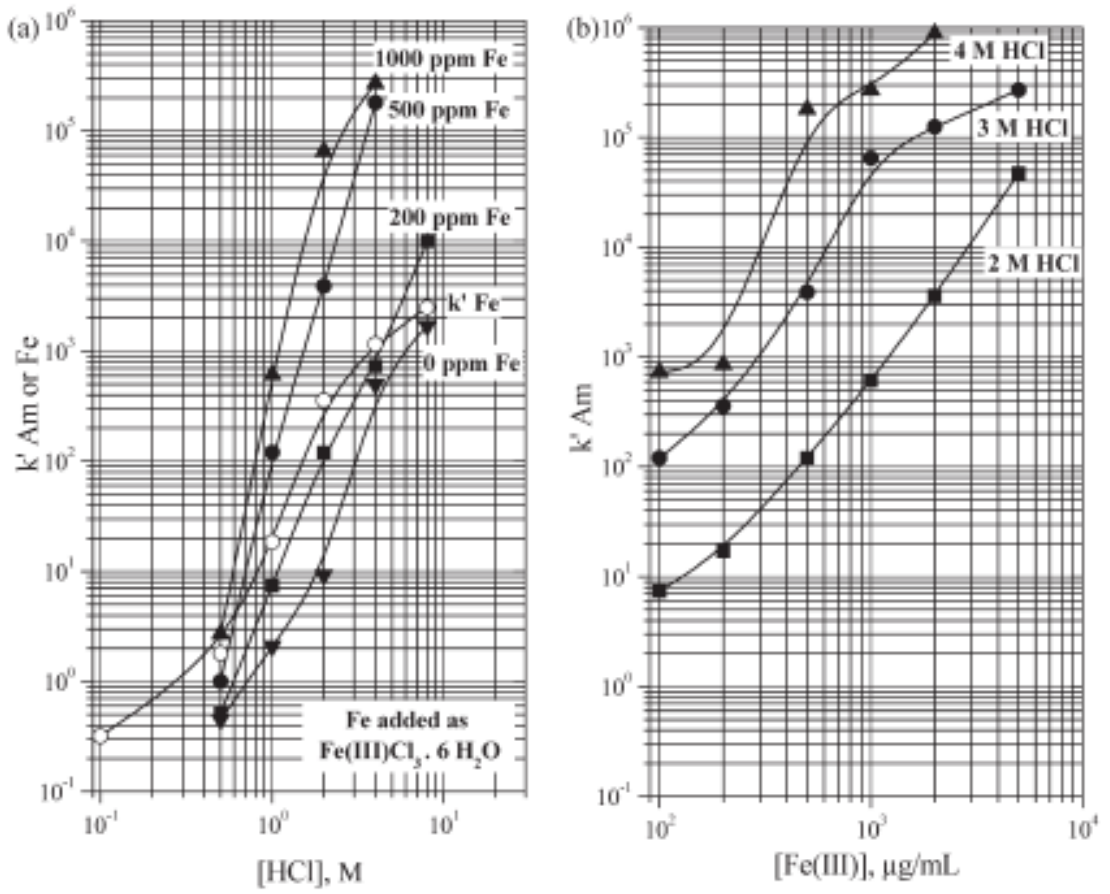

Figure 4 (a) k' Am(III) (solid symbols) and Fe (open symbols) on TODGA resin vs. HCl. (b) k' Am on TODGA Resin from 2 M, 3 M, and 4 M HCl vs. Fe(III). 


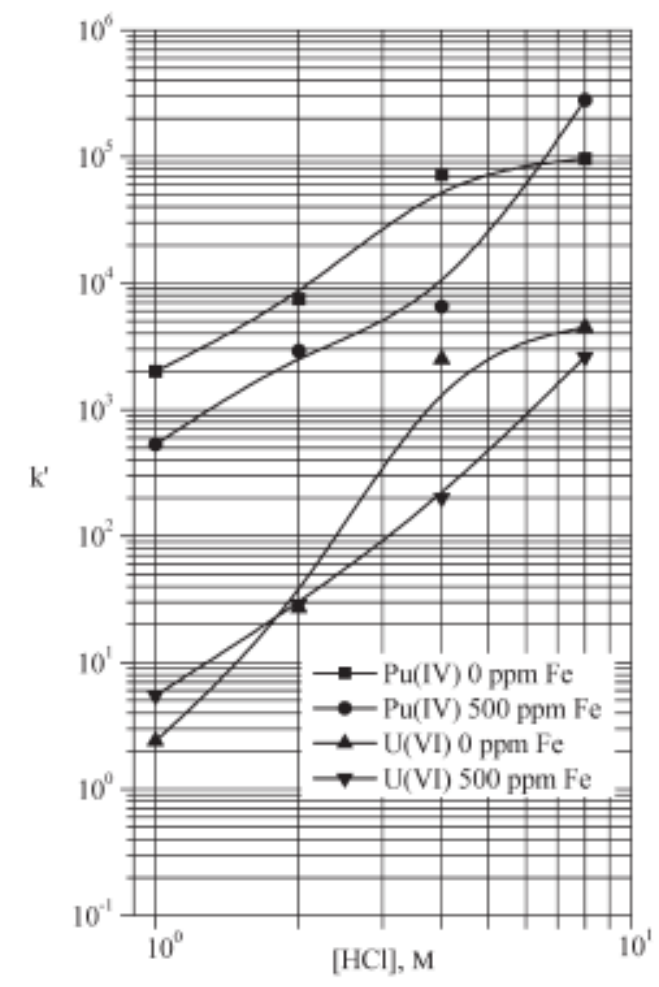

Figure 5 k' U(VI) and Pu(IV) on TODGA resin from $\mathrm{HCl}+\mathrm{FeCl}_{3}$

A consideration of the elements found in spent fuel is very important in obtaining a well characterized system for separation of reprocessing waste streams. Potential interfering elements were identified from a calculation performed using ORIGEN2 for mass and activity percentages with the following assumptions: 1) $30 \mathrm{MWd} / \mathrm{kg} \mathrm{M}$ burnup, 2) 10 year cool down period, 3) $2.9 \%$ initial ${ }^{235} \mathrm{U}$ enrichment.[4] It will be important to study these elements and their affects on the sorption and separation using DGA resin. Once these elements are well characterized for their interference and synergistic effects on $\mathrm{Am}, \mathrm{Cm}$, and Pu sorption in nitric and hydrochloric matrixes, this knowledge will need to be applied to a column in order to optimize an automated system in order to provide an effective and efficient separation scheme. 
Table 1 Spent Fuel Composition

\begin{tabular}{|c|c|c|}
\hline \multicolumn{3}{|c|}{ Ranked by Mass } \\
\hline Rank & Element & Percent \\
\hline 1 & $\mathrm{U}$ & 98.43 \\
\hline 2 & $\mathrm{Pu}$ & 0.85 \\
\hline 3 & $\mathrm{Nd}$ & 0.13 \\
\hline 4 & $\mathrm{Cs}$ & 0.13 \\
\hline 5 & $\mathrm{Ce}$ & 0.1 \\
\hline 6 & $\mathrm{Tc}$ & 0.07 \\
\hline 7 & $\mathrm{Zr}$ & 0.07 \\
\hline 8 & $\mathrm{Am}$ & 0.06 \\
\hline 9 & $\mathrm{~Np}$ & 0.04 \\
\hline 10 & $\mathrm{Sr}$ & 0.04 \\
\hline 11 & $\mathrm{Rb}$ & 0.02 \\
\hline 12 & $\mathrm{Sm}$ & 0.02 \\
\hline 13 & $\mathrm{I}$ & 0.02 \\
\hline 14 & $\mathrm{Cm}$ & 0.01 \\
\hline 15 & $\mathrm{Sn}$ & $<0.00$ \\
\hline
\end{tabular}

\begin{tabular}{|c|c|c|}
\hline \multicolumn{3}{|c|}{ Ranked by Activity } \\
\hline Rank & Element & Percent \\
\hline 1 & $\mathrm{Pu}$ & 22.37 \\
\hline 2 & $\mathrm{Cs}$ & 22.19 \\
\hline 3 & $\mathrm{Ba}$ & 20.23 \\
\hline 4 & $\mathrm{Y}$ & 14.77 \\
\hline 5 & $\mathrm{Sr}$ & 14.77 \\
\hline 6 & $\mathrm{Pm}$ & 1.63 \\
\hline 7 & $\mathrm{Eu}$ & 1.51 \\
\hline 8 & $\mathrm{Kr}$ & 1.09 \\
\hline 9 & $\mathrm{Am}$ & 0.59 \\
\hline 10 & $\mathrm{Cm}$ & 0.33 \\
\hline 11 & $\mathrm{Sb}$ & 0.16 \\
\hline 12 & $\mathrm{Sm}$ & 0.09 \\
\hline 13 & $\mathrm{H}$ & 0.07 \\
\hline 14 & $\mathrm{Rh}$ & 0.06 \\
\hline 15 & $\mathrm{Ru}$ & 0.06 \\
\hline
\end{tabular}

Once the interference studies are performed, it will be necessary to study the separation performance in dynamic column studies. Since the majority of spent fuel is Uranium, it is also necessary to determine the maximum capacity of Uranium on DGA. A theoretical value of $0.56 \mathrm{mmol} \mathrm{U}(\mathrm{VI}) / \mathrm{g}$ DGA has been reported by Horwitz.[5] In case this concentration is exceeded, a UTEVA column could be stacked on top of DGA in order to sorb the Uranium prior to reaching DGA and avoid any influence on the Am, $\mathrm{Cm}$, and Pu uptake.

Weight distributions were calculated using the following equation:

$$
D_{w}=\frac{\left[A_{0}-A_{s} / w\right]}{\left(A_{s} / V\right)}
$$


Rapid Automated Dissolution and Analysis Techniques for Radionuclides in Recycle Process Streams

Where $A_{o}$ and $A_{s}$ are the aqueous phase metal ion concentrations before and after contact, $\mathrm{W}$ is the weight of the resin in grams, and $\mathrm{V}$ is the volume of the aqueous phase in milliliters. The weight distribution is converted to free column volume to peak maximum, $\mathrm{k}$, by the following equation.

$$
k^{\prime}=D_{w} \times 0.57
$$




\section{EXPERIMENTAL DETAILS}

\section{Kinetic Studies}

All studies were performed in batch studies with replicates of five. 50mg of DGA resin was weighed into $2 \mathrm{~mL}$ microcentrifuge tubes and $1.0 \mathrm{~mL}$ desired acid concentration was added to the resin and the vials were agitated on a shaking table for an hour.. After the resin was allowed to settle overnight, $0.5 \mathrm{~mL}$ of $\sim 100 \mathrm{~Bq} / \mathrm{mL}$ standard of $\mathrm{Am}-241$, Cm-44, or Pu-239 was added the next morning. These vials were then shaken for: 10, 20, 30,60 , and 360 minutes. The solutions in each vial were then removed using a transfer pipette and placed in a filtered syringe. Once the solutions were filtered, $0.9 \mathrm{~mL}$ of each sample was then added to $15 \mathrm{~mL}$ of LSC cocktail and analyzed. These vials were counted up to an hour each or until an uncertainty of less than 1 sigma was reached.

\section{Mass Studies}

All studies were performed in batch studies with replicates of five. Varying masses of 15, 50, $100 \mathrm{mg}$ of DGA were weighed into $2 \mathrm{~mL}$ microcentrifuge tubes and $1.0 \mathrm{~mL}$ of 1 and $10 \mathrm{M} \mathrm{HNO}_{3}$ and $\mathrm{HCl}$ acid were added. The vials were then agitated on a shaking table for an hour. After the resin was allowed to settle overnight, $0.5 \mathrm{~mL}$ of $\sim 100$ $\mathrm{Bq} / \mathrm{mL}$ standard of Am-241 or Cm-44 was added the next morning. These vials were then shaken for: 10, 20, 30, 60, and 360 minutes. The solutions in each vial were then removed using a transfer pipette and placed in a filtered syringe. Once the solutions were filtered, $0.9 \mathrm{~mL}$ of each sample was then added to $15 \mathrm{~mL}$ of LSC cocktail and analyzed. These vials were counted up to an hour each or until an uncertainty of less than 1 sigma was reached.

\section{Adsorption Studies}

All studies were performed in batch studies with replicates of five. 50mg of DGA resin was weighed into $2 \mathrm{~mL}$ microcentrifuge tubes and $1.0 \mathrm{~mL}$ desired acid concentration 
was added to the resin and the vials were agitated on a shaking table for an hour. After the resin was allowed to settle overnight, $0.5 \mathrm{~mL}$ of $\sim 100 \mathrm{~Bq} / \mathrm{mL}$ standard of $\mathrm{Am}-241$, Cm-44, or Pu-239 was added the next morning and shook for 1 hour on a shaking table. The solutions in each vial were then removed using a transfer pipette and placed in a filtered syringe. Once the solutions were filtered, $0.9 \mathrm{~mL}$ of each sample was then added to $15 \mathrm{~mL}$ of LSC cocktail and analyzed. These vials were counted up to an hour each or or until an uncertainty of less than 1 sigma was reached.

\section{Capacity Studies}

Initial capacity studies were performed by doing batch studies the same as the sorption studies procedure. For further analysis of the capacity a $2 \mathrm{~mL}$ column was slurry packed to $1 \mathrm{~mL}$. The resin was wetted and rinsed with $1 \mathrm{M} \mathrm{HNO}_{3}$. In $0.1 \mathrm{M} \mathrm{HNO}_{3}, 4.44$, 22.2, and $44.4 \mathrm{mg}$ of $\mathrm{U}(\mathrm{VI}) / \mathrm{mL}$ loading solutions were eluted from the column by gravity. Five drop aliquots were added to $15 \mathrm{~mL}$ LSC cocktail and were counted up to an hour each or until an uncertainty of less than 1 sigma was reached. 


\section{RESULTS AND DISCUSSION}

\section{Verification of Procedure}

For both resins the adsorption for Americium, Curium, and Plutonium was confirmed to match the trends reported for sorption characteristics with Horwitz data in $\mathrm{HCl}$ and $\mathrm{HNO}_{3}$ matrices.

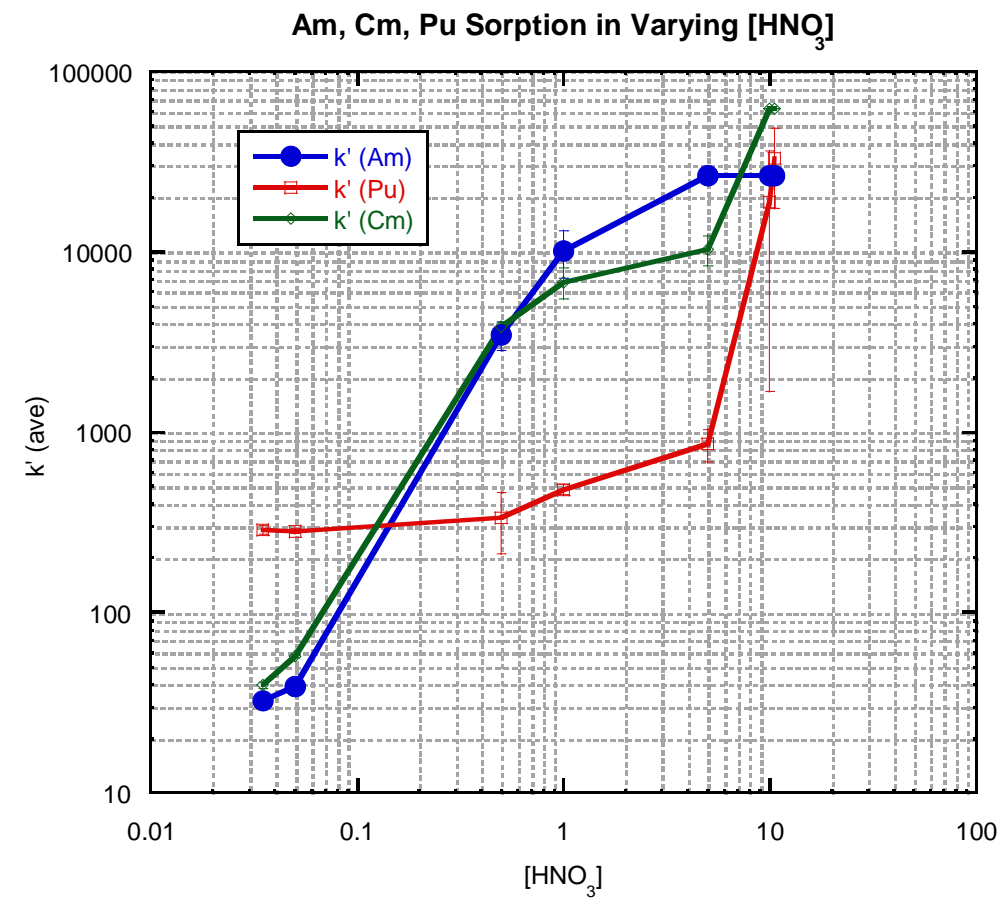

Figure 6 Sorption of $\mathrm{Am} / \mathrm{Cm} / \mathrm{Pu}$ on DGA Resin in $\mathrm{HNO}_{3}$ 


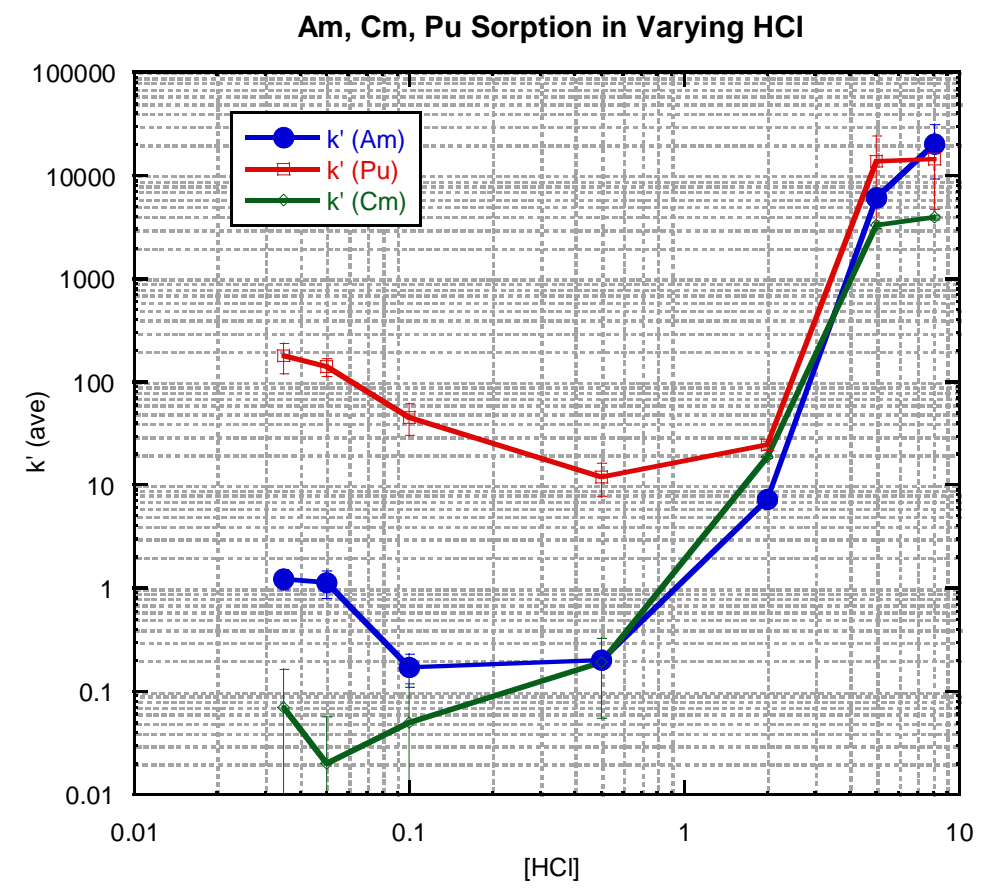

Figure 7 Sorption of Am/Cm/Pu on DGA Resin in HNO3

The study of the kinetics of the interaction between $\mathrm{Am}, \mathrm{Cm}$ and $\mathrm{Pu}$ and the DGA resin was accomplished for both $\mathrm{HCl}$ and $\mathrm{HNO}_{3}$ systems at times of 10, 30, 60, and 360 minutes. The study of $1 \mathrm{M}$ and $10 \mathrm{M}$ acids determined the time at which equilibrium is reached is before the 30 minute mark as the k' values level off at that point. 
Rapid Automated Dissolution and Analysis Techniques for Radionuclides in Recycle Process Streams
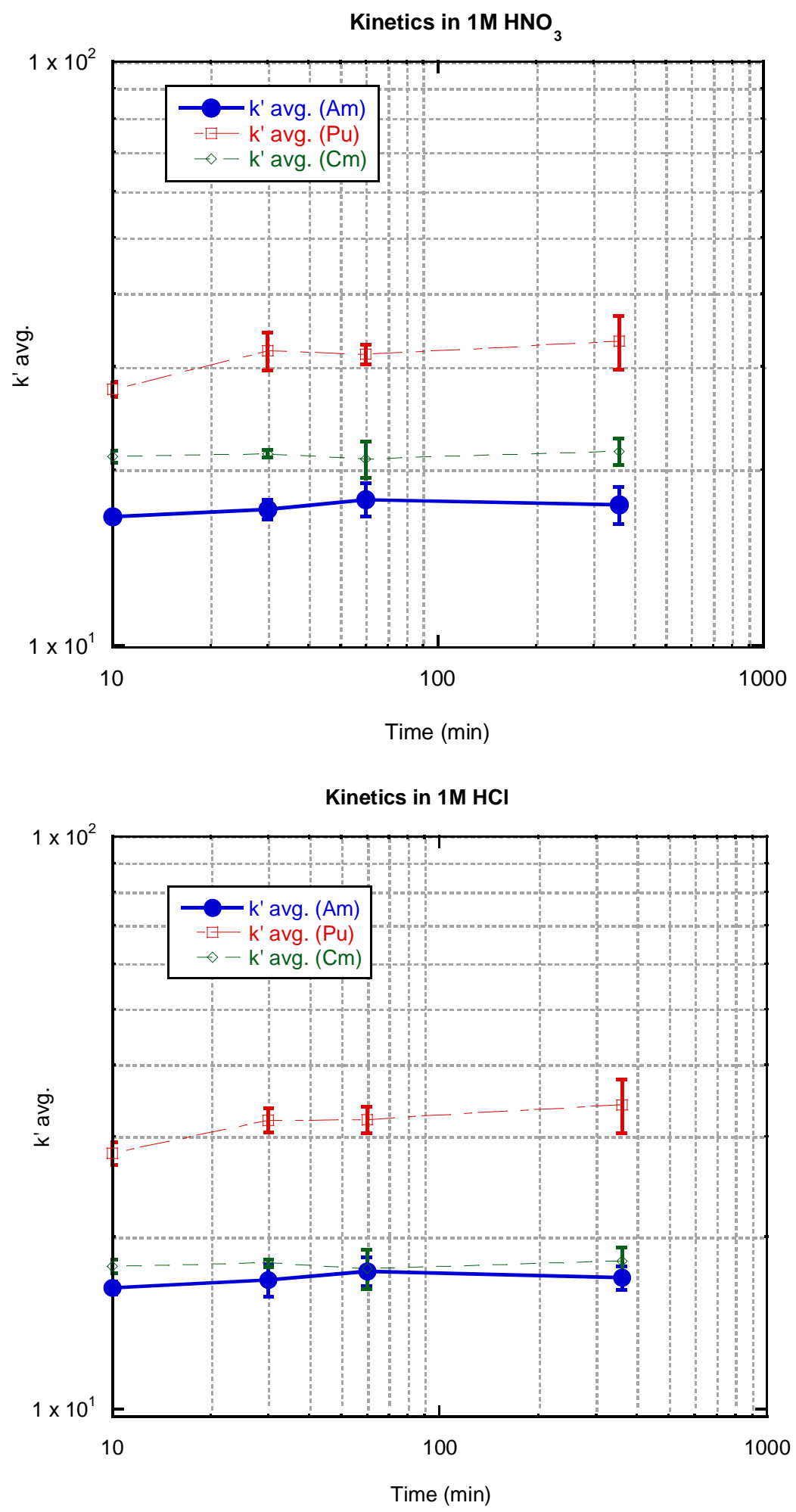
Kinetics in $10 \mathrm{M} \mathrm{HNO}_{3}$

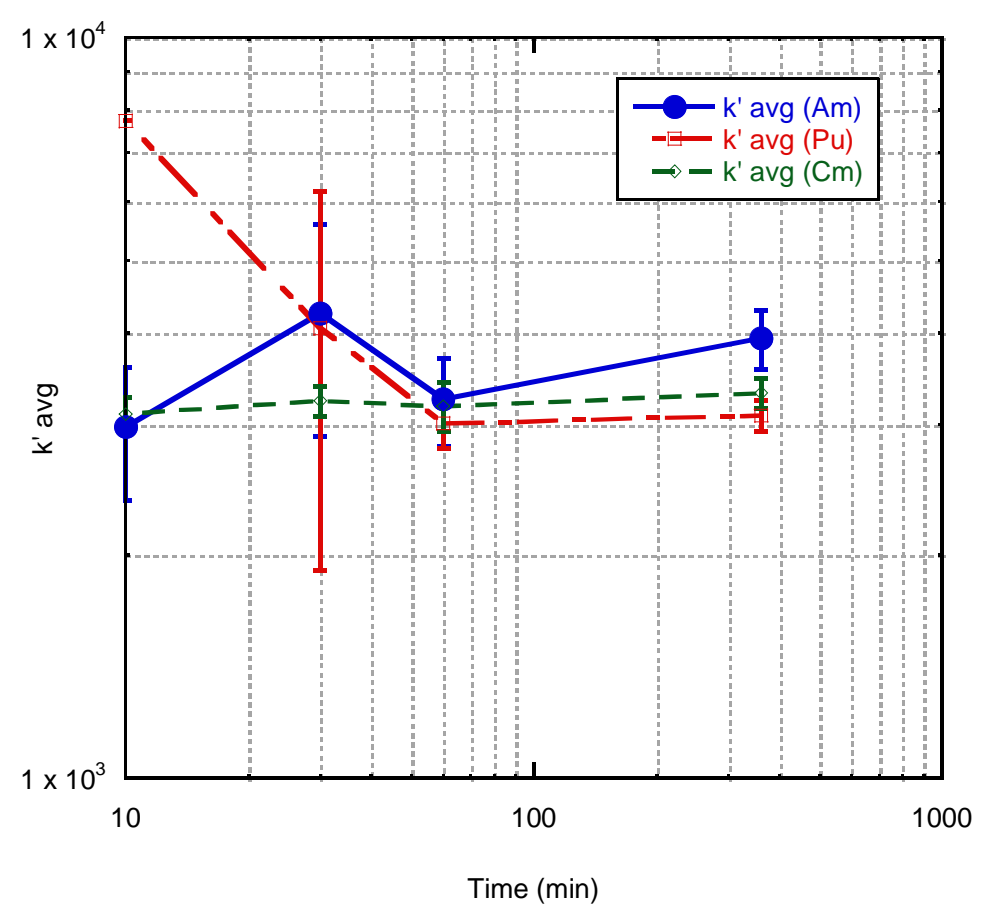

Kinetics in $10 \mathrm{M} \mathrm{HCl}$

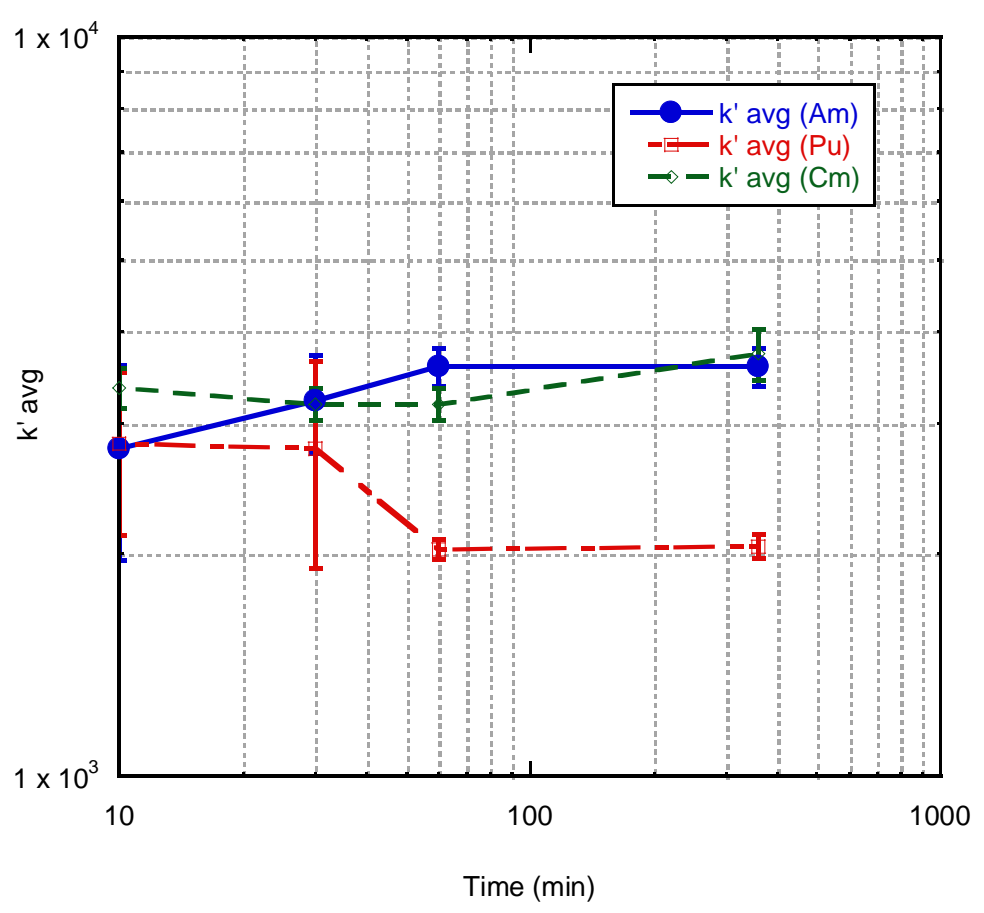


This confirms that a mixing time of one hour is sufficient for further absorption studies. The independence of the k' values from resin mass were re-studied as initially there were unexplainable variances in the data but additional results show that the $k$ ' values are independent of the resin mass used, as can be expected.

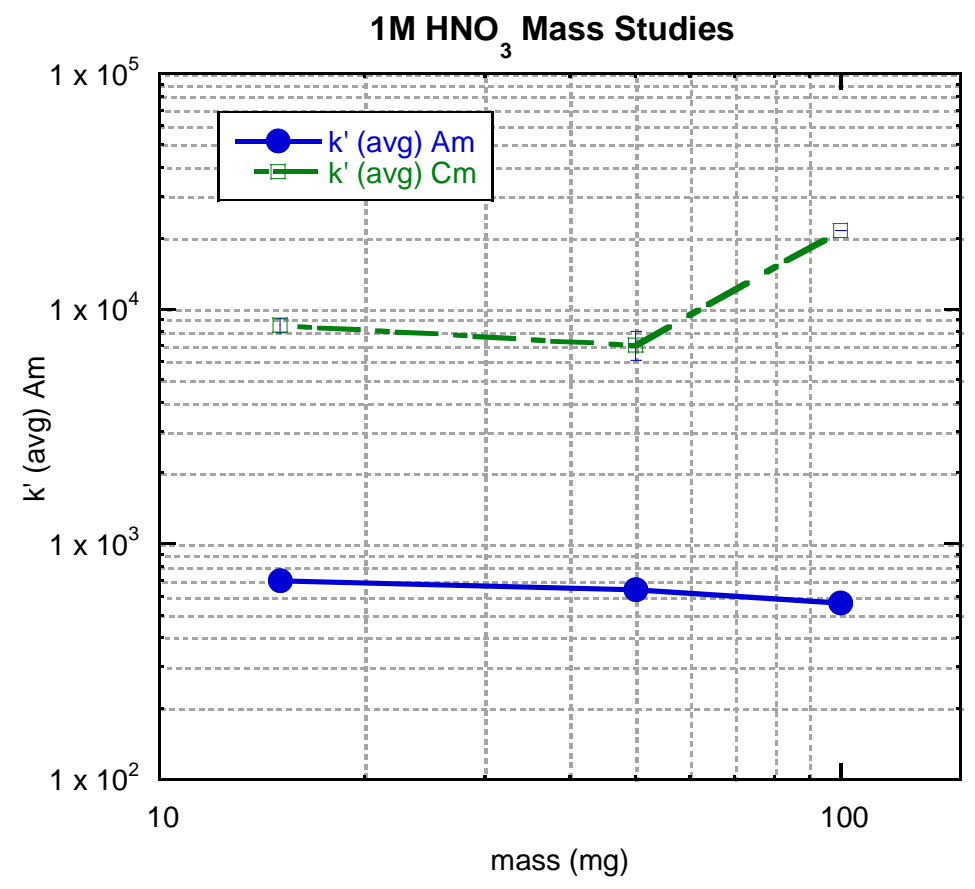

These previous studies proved that that procedure utilized accurate and effective since published data could be reproduced. In addition it provided reassurance that equilibrium was reached prior to filtrating and that the k' values are independent of the resin mass used. 


\section{Interference Studies}

A literature research was performed to determine the most appropriate metals to be studied for possible interferences based on mass percentage and activity percentage found in waste streams and from any reprocessing components used. It is important to analyze the interference affects of those metals which have the highest concentration and affinity for DGA. This list was based off of the analysis of the contents in the dissolved fuel, as listed Table 1. After analyzing published data, the top elements which may show interference on the adsorption of $\mathrm{Am}, \mathrm{Cm}$, and Pu sorption were identified as: $\mathrm{U}, \mathrm{Nd}, \mathrm{Ce}$, $\mathrm{Tc}, \mathrm{Zr}, \mathrm{Np}$, Sr, and $\mathrm{Rb}$ (some adsorption in $\mathrm{HCl}$ systems).

The first metal studied for interference was Zirconium. The concentrations studied were: $0.1,0.3,0.5,1.0,1.3 \mathrm{M} \mathrm{Zr}\left(\mathrm{SO}_{4}\right)_{2}$ solutions for $1 \mathrm{M} \mathrm{HCl}$ and $\mathrm{HNO}_{3}$ solutions. All experiments were performed with 5 replicates. Standards of 1, 15, 25, 50, 75 and 100 ppm solutions of $\mathrm{Zr}\left(\mathrm{SO}_{4}\right)_{2}$ were made in order to quantify working solutions using the ICP-AES. These calibration curves will also be used to quantify the amount of $\mathrm{Zr}$ in eluent after spiking, shaking, and filtering. The determination of the $\mathrm{Zr}$ concentration allowed to understand how $\mathrm{Zr}$ is interfering with the sorption of $\mathrm{Am}, \mathrm{Cm}$, and Pu. The concentrations of Am, Cm, and Pu were analyzed on LSC. 

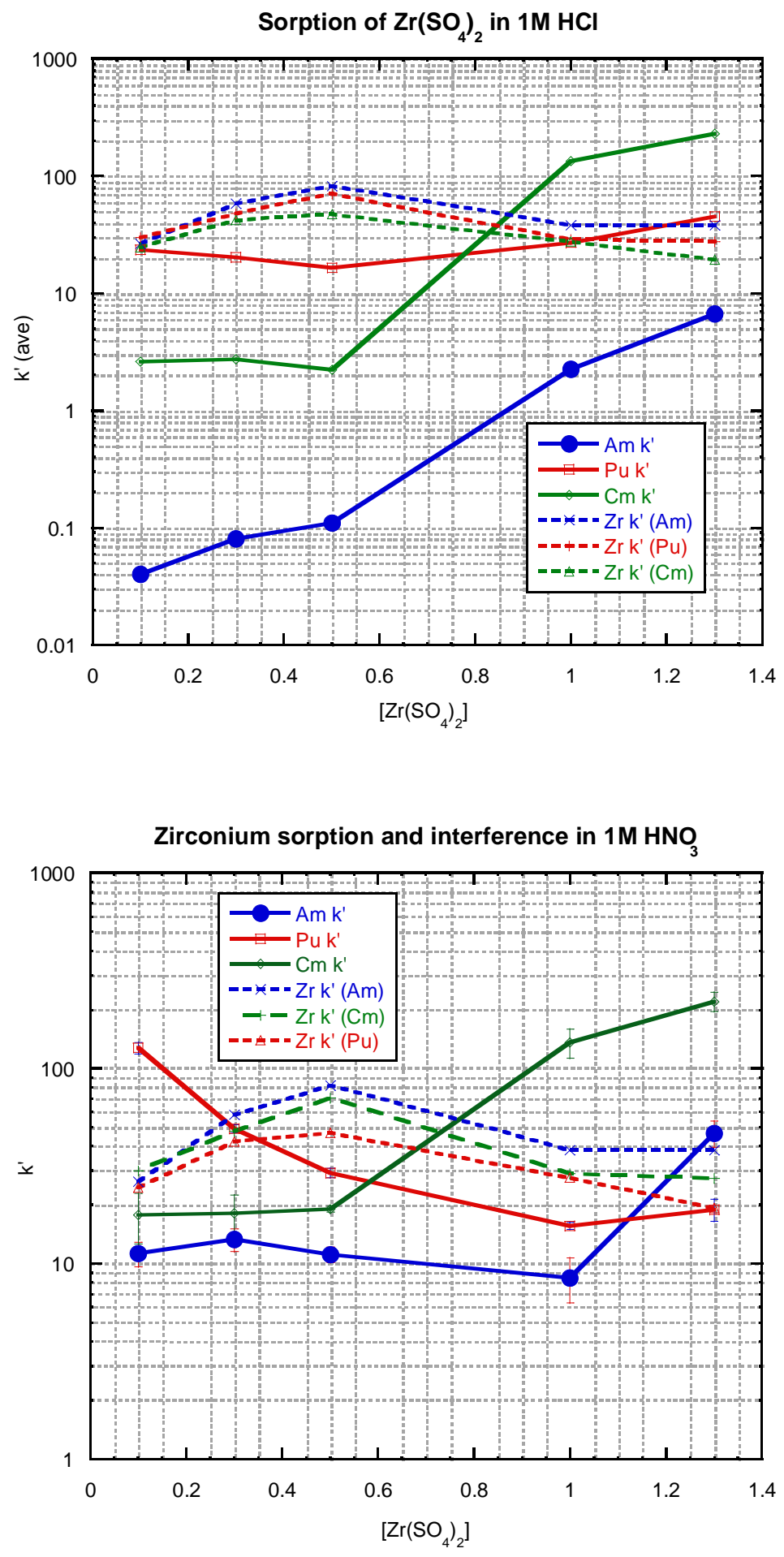
In the above two graphs, the Zirconium interference studies in $1 \mathrm{M} \mathrm{HNO}_{3}$ and $\mathrm{HCl}$ data is represented. The solid lines are the $\mathrm{Am}, \mathrm{Cm}$, and $\mathrm{Pu}$ activities in the eluents; whereas, the dotted lines are the concentrations of $\mathrm{Zr}$ with respect to the $\mathrm{Am}, \mathrm{Cm}$, or $\mathrm{Pu}$ set. As seen in the two above graphs, there appears to be an inverse correlation between the $\mathrm{Zr}$ and $\mathrm{Am}$, Cm sorption onto the resin. This implies that there is a competition between $\mathrm{Zr}$ and $\mathrm{Am}, \mathrm{Cm}$ on the resin. For $\mathrm{Pu}$, there does not appear to be a correlation between the amount of $\mathrm{Zr}\left(\mathrm{SO}_{4}\right)_{2}$ and it's sorption. No definitive conclusions can be made from these results since the contribution of the sulfates are unknown in this system.

To elucidate the $\mathrm{Zr}$ effect on the $\mathrm{Am}, \mathrm{Cm}$ and $\mathrm{Pu}$ sorption, the possible interference of sulfate has to be ruled out. To obtain some preliminary data, the Am, Cm, and $\mathrm{Pu}$ sorption characteristics in $\mathrm{H}_{2} \mathrm{SO}_{4}$ were investigated. This data is seen below, and shows that trends seen in the $\mathrm{Zr}\left(\mathrm{SO}_{4}\right)_{2}$ study for Plutonium were driven by the sulfate and not Zirconium. With this knowledge, the effects of Zirconium with another anion which will not have as great of an impact on the sorption need to be studied.

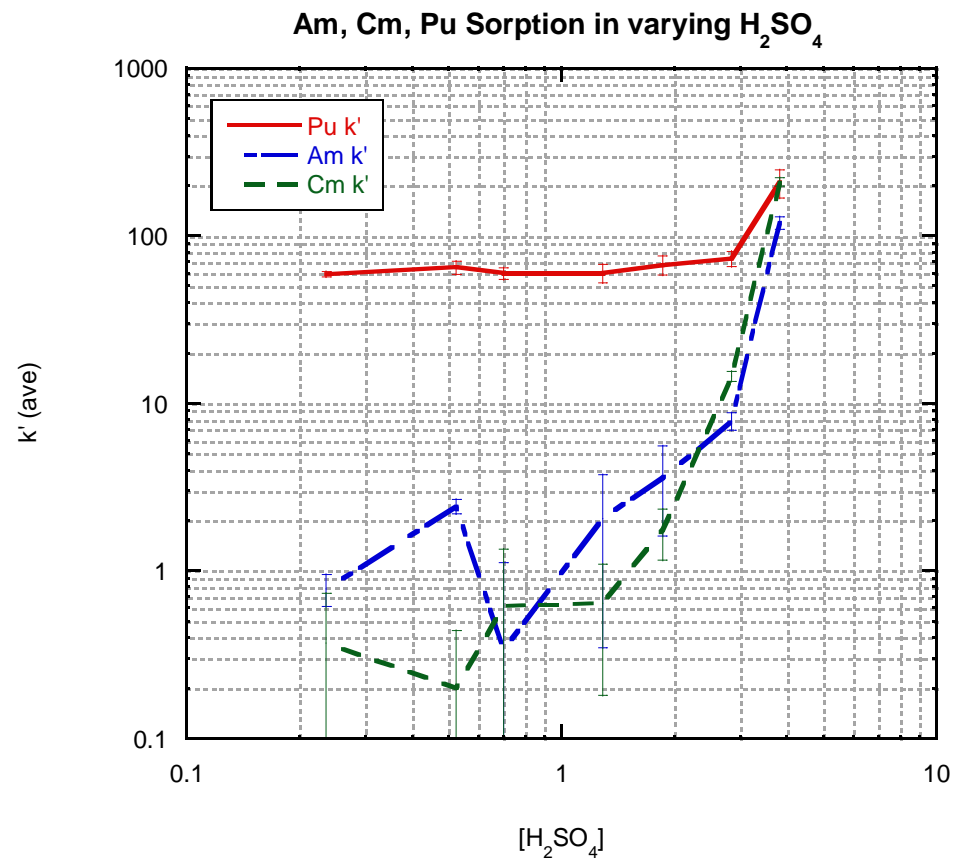


To further clarify the effect of the sulfates in the nitric and chloric matrices, $\mathrm{Na}_{2} \mathrm{SO}_{4}$ at 2.0, 1.5, 1.0, 0.5, $0.1 \mathrm{M}$ in $1 \mathrm{M} \mathrm{HNO}_{3}$ and $\mathrm{HCl}$ was studied. These experiments were again performed in replicates of 5 . The $\mathrm{Na}$ form of the sulfate was used due to its low affinity for DGA resin and it was assumed that it would have little to no effect on the sulfate/nitrate and sulfate/chloride interaction. In the graphs displayed below, very different results were seen than those in Zirconium Sulfate studies. This could either be attributed to sodium having an affect or that these trends are caused by the presence of Zirconium.

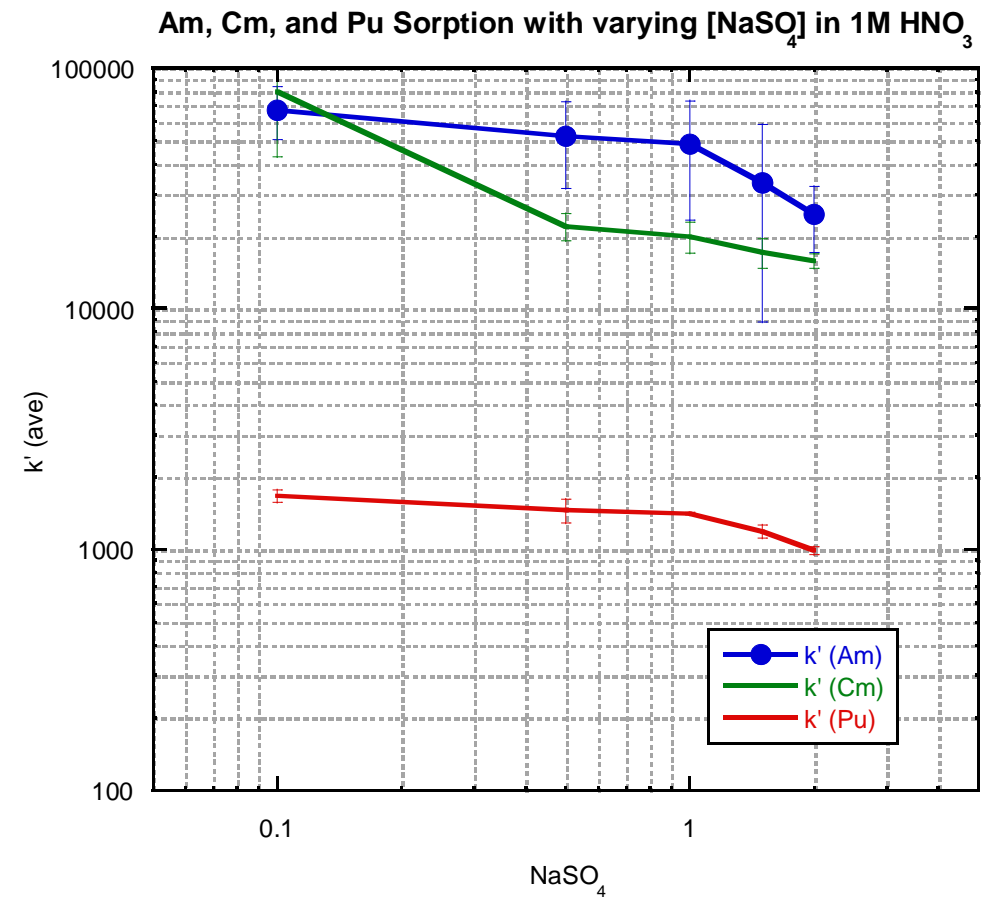




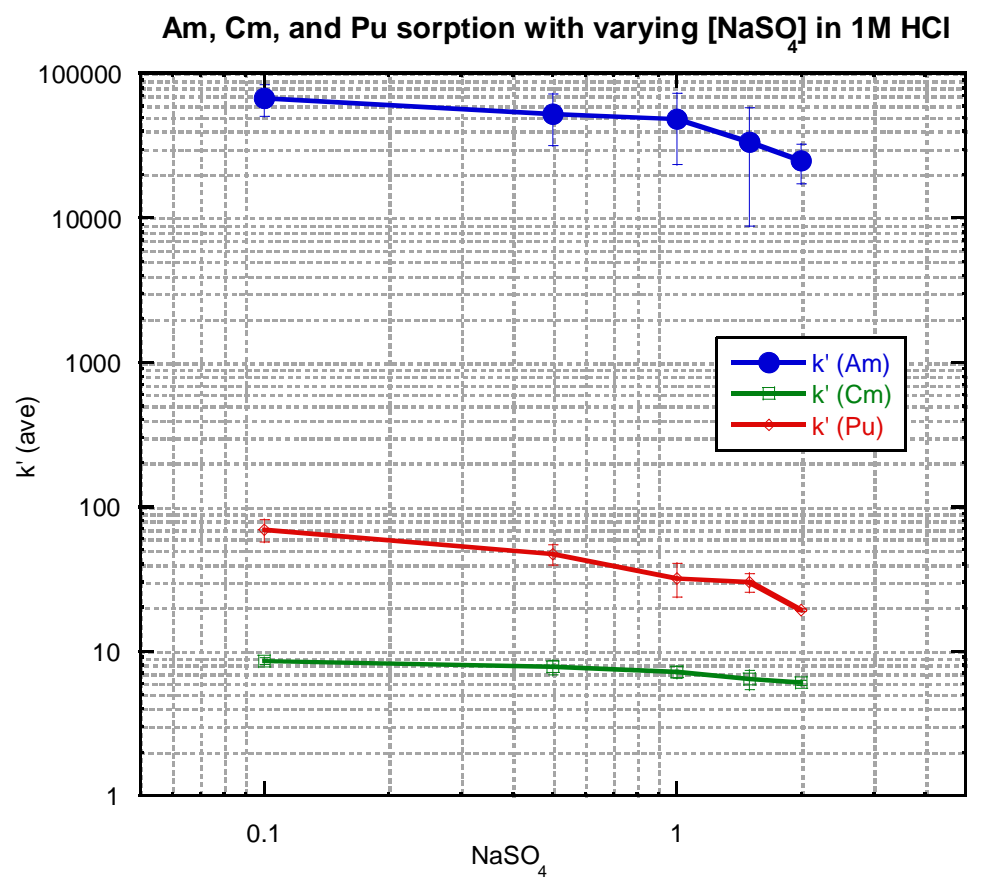

Iron concentrations studied were: $0.05,0.1,0.3,0.5,0.75,1.0 \mathrm{M} \mathrm{FeBr}_{2}$ solutions for $1 \mathrm{M} \mathrm{HCl}$ and $0.1,0.3,0.5,1.0,2.0,3.0 \mathrm{M}$ for $1 \mathrm{M} \mathrm{HNO}_{3}$ systems. Standards of 1, 15, 25, 50, 75 and 100 ppm solutions of $\mathrm{FeBr}_{2}$ were made in order to quantify working solutions using the ICP-AES. These calibration curves were also used to quantify the amount of Fe in eluent after spiking, shaking, and filtering. The determination of the Fe concentration will allow to understand how Fe is interfering with the sorption of Am, $\mathrm{Cm}$, and Pu whether it's on the resin or in the eluent. The concentration of Am, Cm, and $\mathrm{Pu}$ were analyzed on the LSC. 


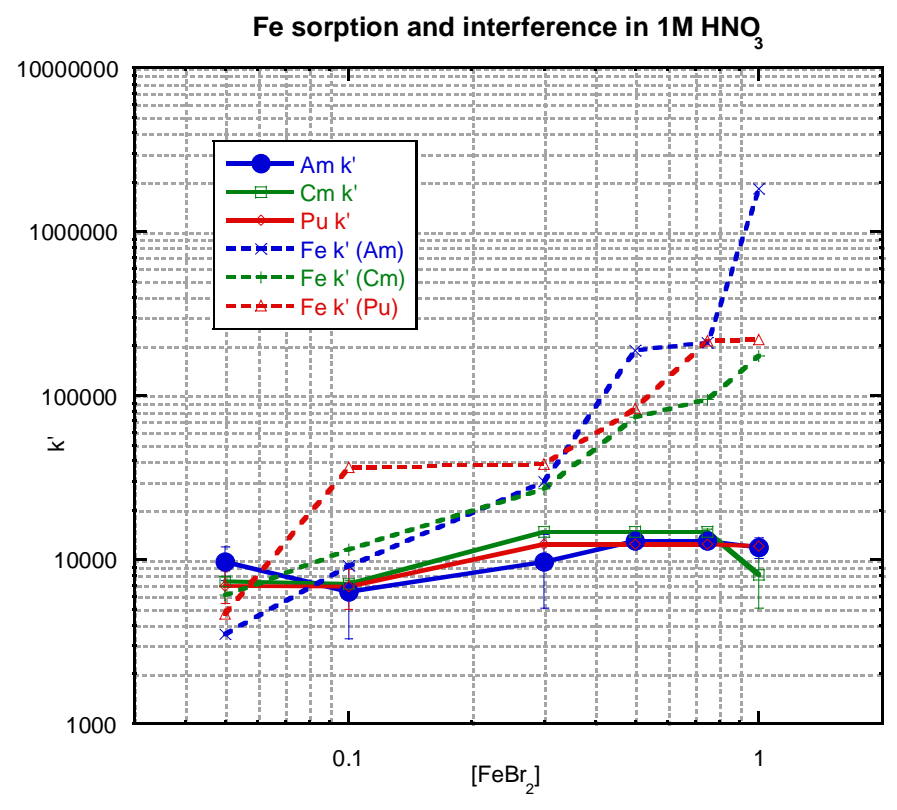

For $\mathrm{Fe}(\mathrm{II})$ interferences in $\mathrm{HNO}_{3}$ matrices, it is seen that there is an increased Fe(II) sorption but the actinide sorption has little to no increase. This may be due to the fact that those values are reaching the detection limits of the LSC and in reality may be higher than detected and actually follow the same trends as Fe sorption. To see this effect, a higher initial concentration of Am, Cm, and Pu would be needed. 


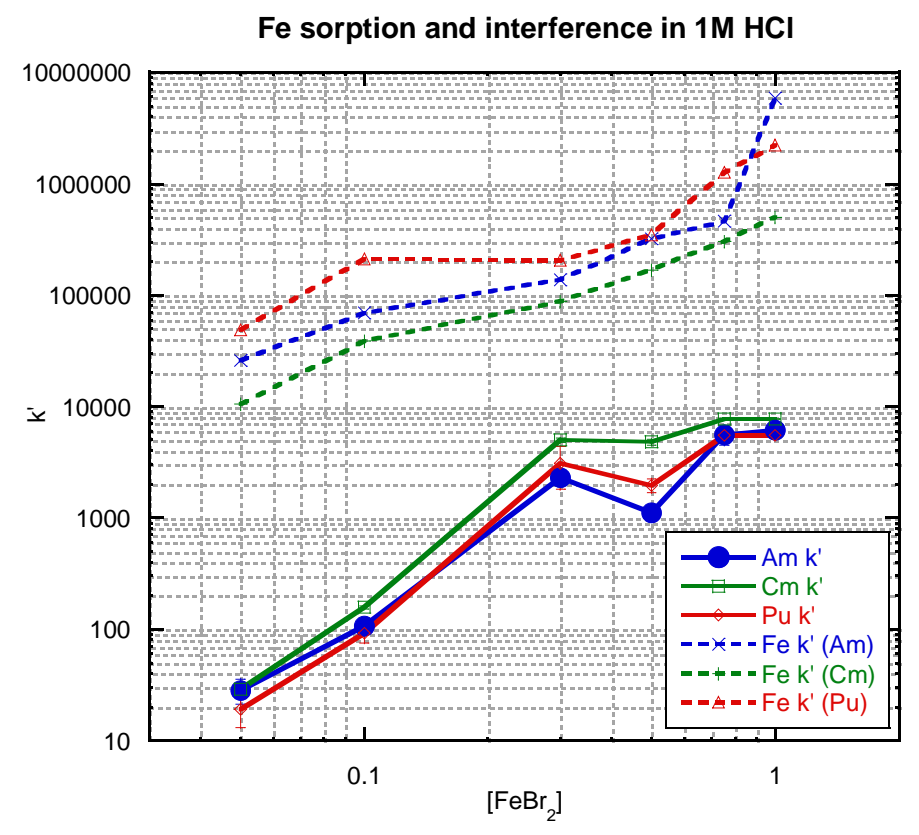

There is a synergistic affect seen in the $\mathrm{HCl}$ systems. As the actinide sorption increases, the Fe sorption increases as well. This supports Horowitz's theory that formation of $\mathrm{Ac}\left(\mathrm{FeCl}_{3}\right)_{3}(\mathrm{DGA})$ does occur.

Prior to determining Technetium's interference effects on $\mathrm{Am}, \mathrm{Cm}$, and $\mathrm{Pu}$, the sorption of Tc needs to be studied as it may help in explaining potential interference effects. Hence, Tc sorption characteristics were analyzed over a wide range of acid concentrations in $\mathrm{HNO}_{3}$ and $\mathrm{HCl}$ matrices. As seen in the $\mathrm{HNO}_{3}$ graph, the k' values for Technetium starts at $10^{4}$ and after $1 \mathrm{M}$ the $\mathrm{k}^{\prime}$ values lowers over an order of magnitude as the $\mathrm{HNO}_{3}$ concentration increases. This is most likely due to the formation of $\mathrm{HTCO}_{4}$. For $\mathrm{HCl}$ matrices, $\mathrm{k}^{\prime}$ is above $10^{3}$ and increases above $10^{4}$. Above $1 \mathrm{M}$, we start to see large error which could be contributed to two different factors. There is a possibility of a $\mathrm{TcCl}^{2-}$ kinetically growing in at the higher concentrations or that the LSC detection limit is being reached. 

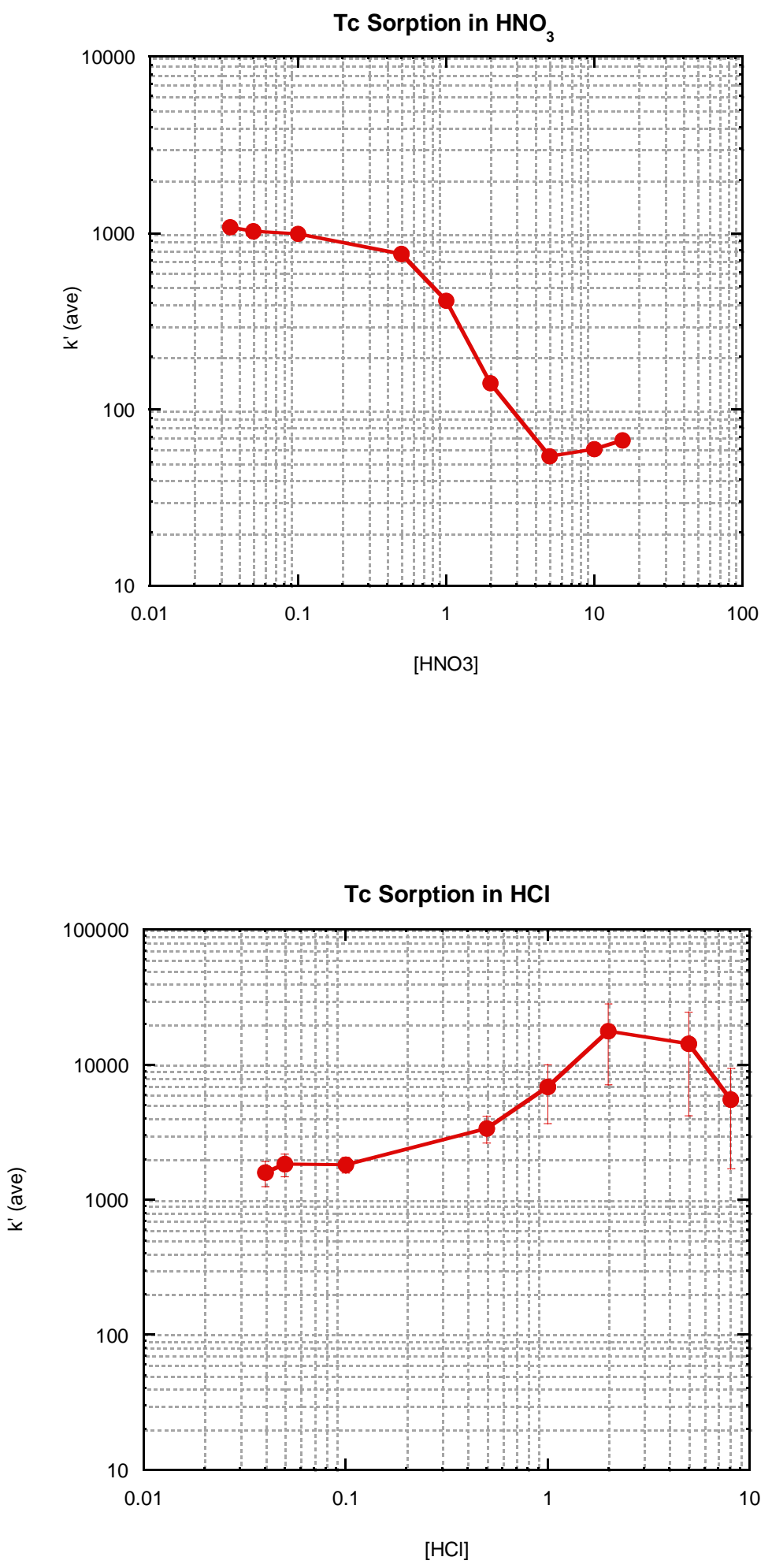
To determine, if there were any different Technetium species growing in over time, the adsorption kinetics were determined for two separate acid concentrations. $1 \mathrm{M}$ was studied so that there would be plenty of room above and below the k' values to see a change. Since the $\mathrm{TcCl}^{4-}$ specie in growth would be most predominating in high acid concentrations $10 \mathrm{M}$ was also studied.
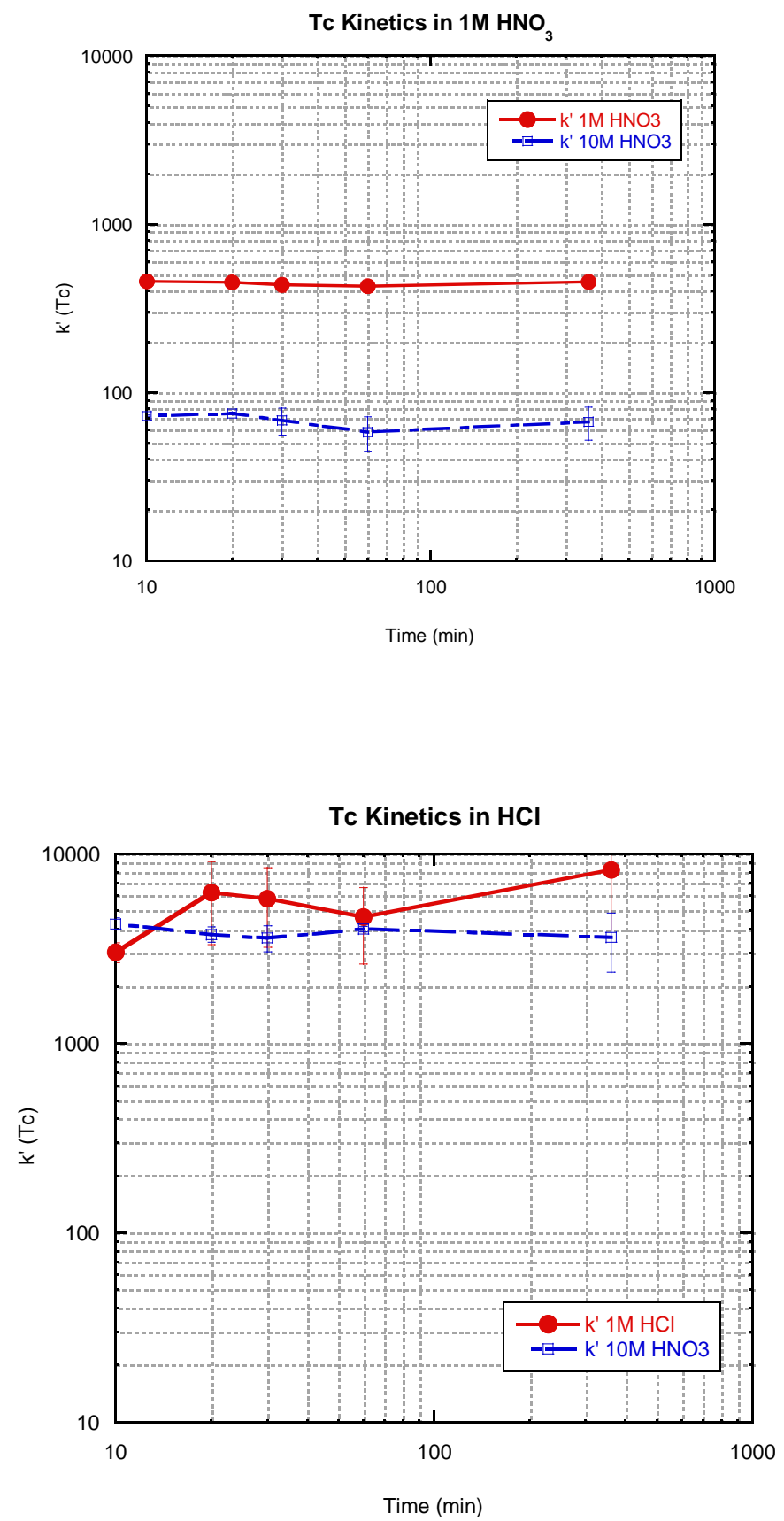
Equilibrium was reach for both acid concentrations in both matrices after 10 minutes. The error bars seen in these graphs were due to the fact that the detection limit on the LSC was reached.

Technetium interference was studied at 130, 100, 90, 80, 70, $60 \mathrm{~Bq} / \mathrm{mL}$ in $1 \mathrm{M}$ $\mathrm{HNO}_{3}$ and $\mathrm{HCl}$. A co-complex of $\mathrm{Am}\left(\mathrm{TcO}_{4}\right)_{\mathrm{x}}(\mathrm{DGA})_{\mathrm{x}}$ is seen for $\mathrm{Am}$ and $\mathrm{Cm}$ in nitric matrices. In these interference studies the $\mathrm{k}^{\prime}$ values are increased from $10^{4}$ to $10^{5}$ for $\mathrm{Am}$. There is a slight decrease of Pu uptake in the presence of Tc. This infers that there is a competition for active sites on the resin.

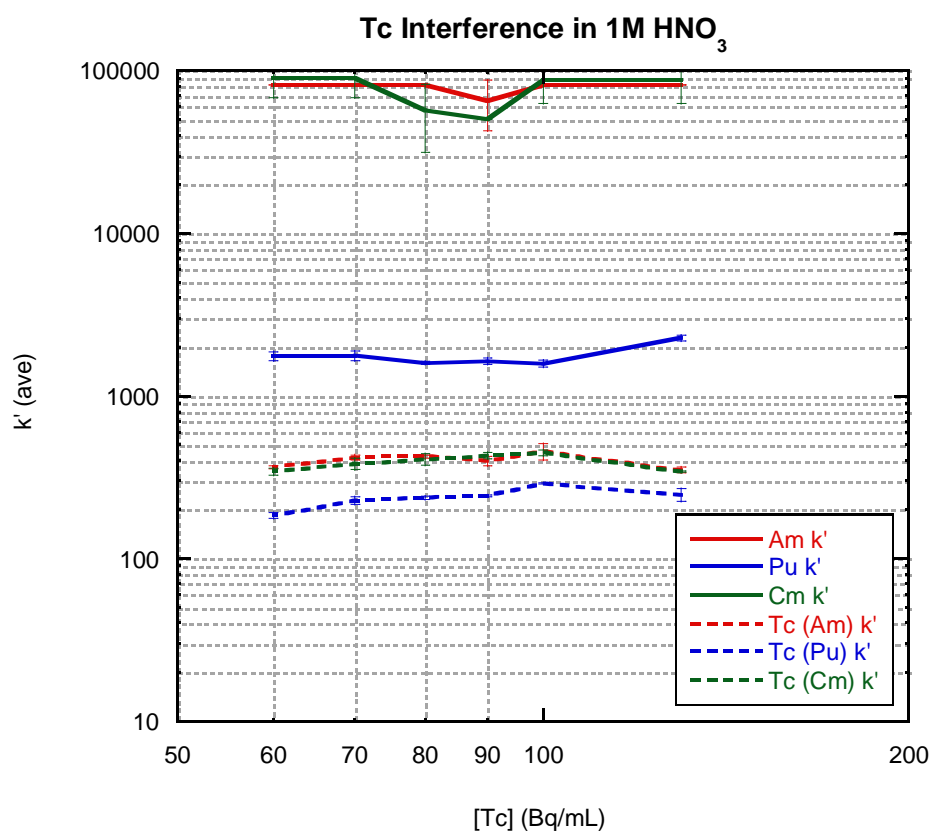

In $\mathrm{HCl}$ matrices a large increase is seen for Am sorption, going from $\mathrm{k}^{\prime} 10^{0}$ to $10^{2}$. For Pu there is a significant decrease in its k' value, $10^{3}$ to $10^{2}$. There is a large amount of error for this data, because the larger activity resulted in an increased alpha/beta spillover. 


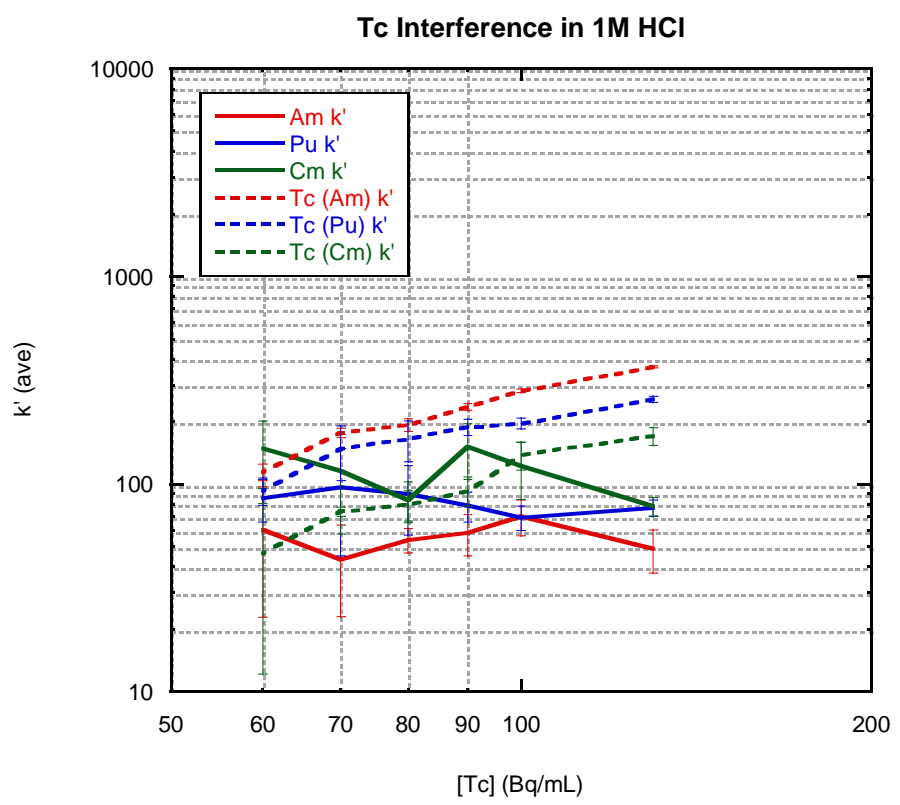

Neodymium interference has also been studied at 2.5, 2.0, 1.0, 0.5, $0.1 \mathrm{M}$ $\mathrm{Nd}\left(\mathrm{NO}_{3}\right)_{3}$ and $\mathrm{NdCl}_{3}$ in $1 \mathrm{M} \mathrm{HNO} 3$ and $\mathrm{HCl}$. These experiments were run in replicates of four. Standards of 1, 5, 15, 25, 50, 75 and 100 ppm solutions of $\mathrm{Nd}(\mathrm{III})$ were made in order to quantify working solutions using the ICP-AES. These calibration curves will also be used to quantify the amount of $\mathrm{Nd}$ in eluent after spiking, shaking, and filtering. The determination of the Nd concentration will allow to understand how $\mathrm{Nd}$ is interfering with the sorption of $\mathrm{Am}, \mathrm{Cm}$, and Pu whether it's on the resin or in the eluent. The concentration of Am, Cm, and Pu were analyzed on the LSC. The LSC results for this study are shown below where it is seen that Pu has differing characteristics from Am and $\mathrm{Cm}$ in $1 \mathrm{M} \mathrm{HCl}$ and $\mathrm{HNO}_{3}$. 

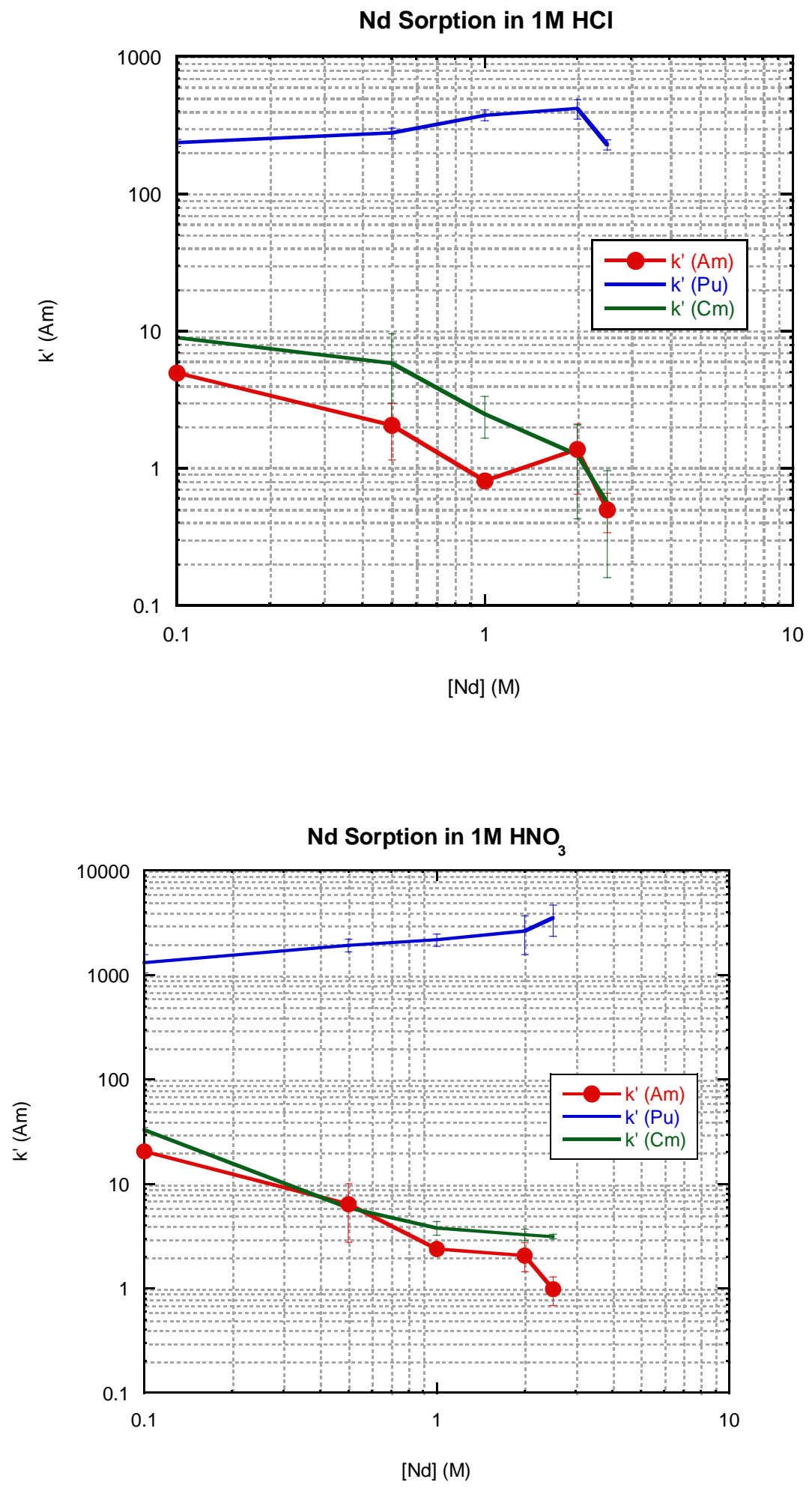
Unfortunately upon analyzing the Nd samples on the ICP-AES it was found that the calibration curve was not sufficient for a reliable analysis. For this reason, new $\mathrm{Nd}$ standards and some method development had to be performed to achieve the optimal results by ICP-AES analysis. Once this was completed, only small amounts of Nd were found to sorb to the rein, which is not what is expected. In other published results by Horwitz Nd has a high k' value to DGA and therefore is expected to compete and have a k' value around $10^{3}$ for $1 \mathrm{M} \mathrm{HNO}_{3}$ and $\mathrm{HCl}$.

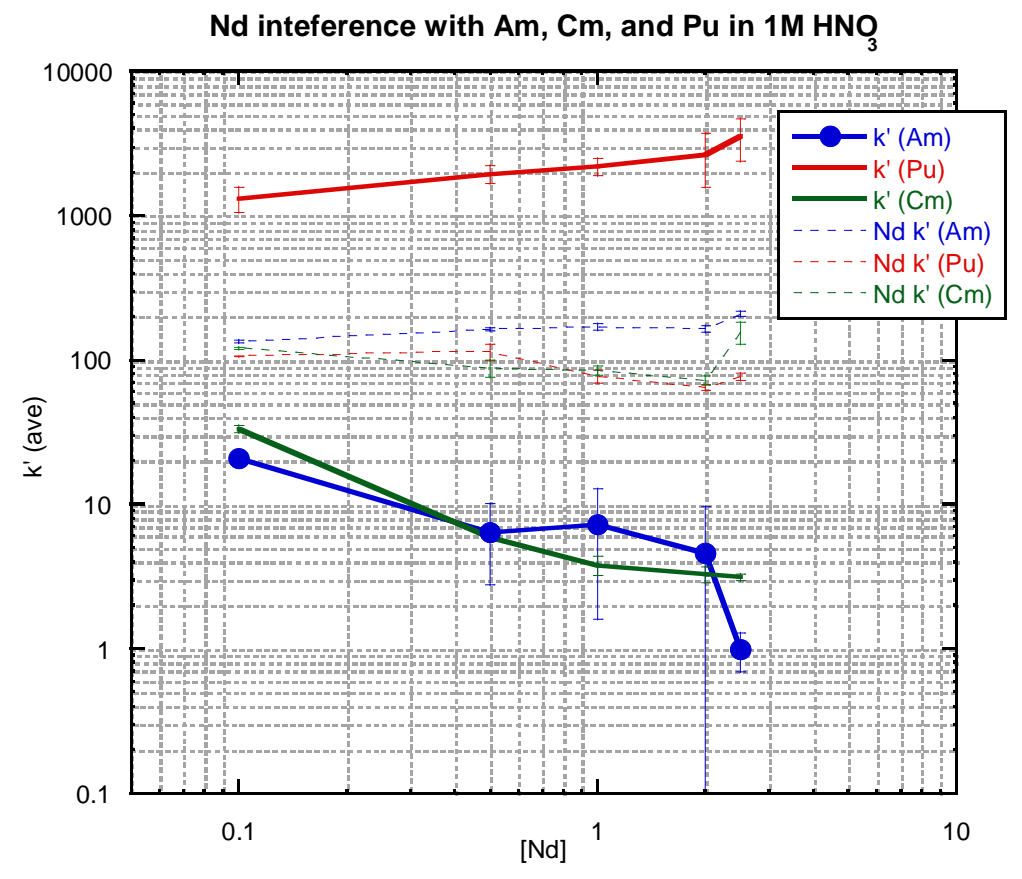




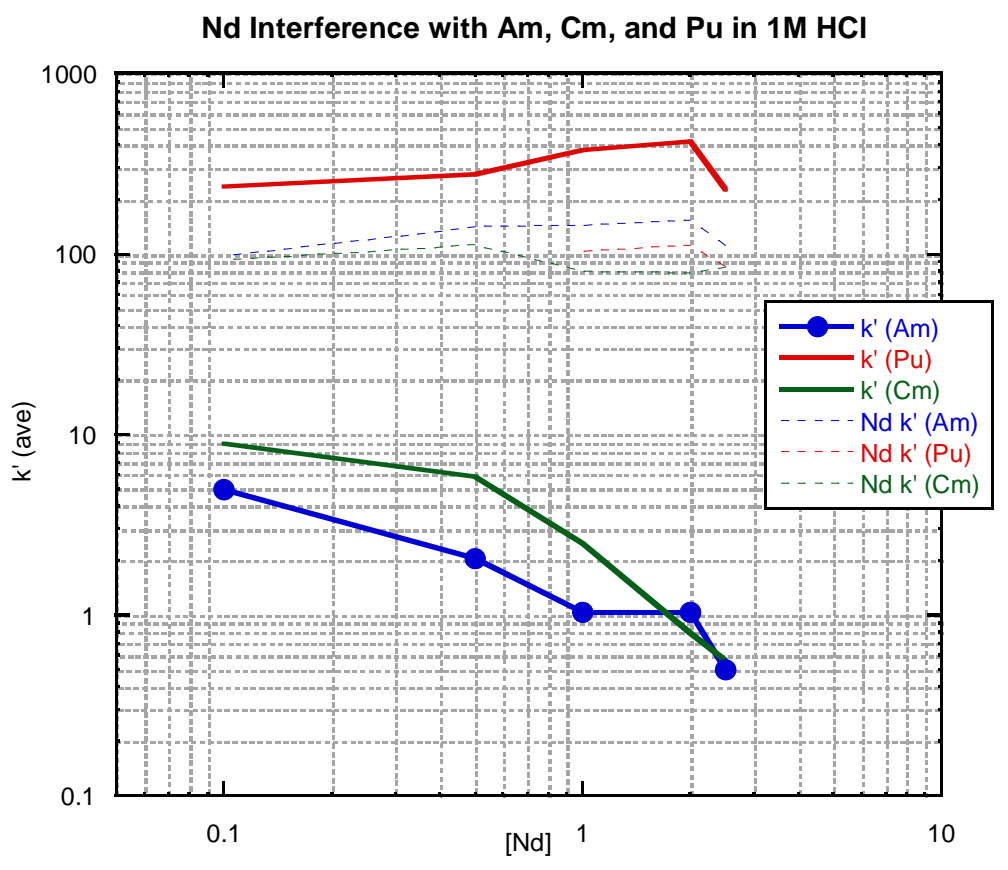

The fact that no changes in $\mathrm{Nd}$ concentration were seen may be caused by the capacity of the resin for $\mathrm{Nd}$ being exceeded. Assuming that $\mathrm{Nd}$ has a similar capacity as a $\mathrm{U}(\mathrm{VI})$, then the capacity would already be exceeded at the lowest concentration. To determine exactly how Nd is interfering, the adsorption behavior will need to be studied at lower concentrations. 


\section{Capacity Studies}

Before studying the interference effects due to Uranium in the system, it was important to understand DGA's capacity for U(VI) due to it being the largest component in the spent fuel. Since Horwitz predicted that DGA has a capacity of $0.56 \mathrm{mmol}$ $\mathrm{U}(\mathrm{VI}) / \mathrm{mg}$ DGA, the capacity studies went below and above $3.33 \mathrm{mg} \mathrm{U}(\mathrm{VI}) / \mathrm{mg}$ DGA as seen below. The capacity was reached as predicted in $\mathrm{HCl}$ but was not in $\mathrm{HNO}_{3}$. The continual increase of the $\mathrm{k}^{\prime}$ value for $\mathrm{U}(\mathrm{VI})$ in DGA is most likely due to the fact that more U(VI) is being loosely coordinated to each DGA. Unfortunately this does not give us conclusive results for $\mathrm{HNO}_{3}$ capacity this will need to be studied further.

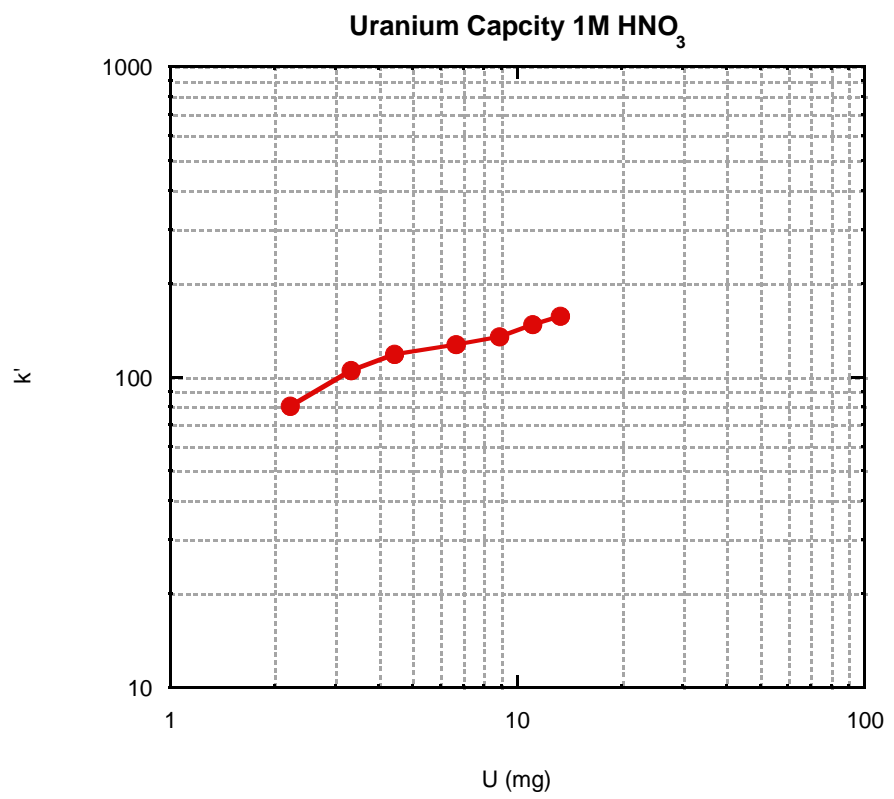




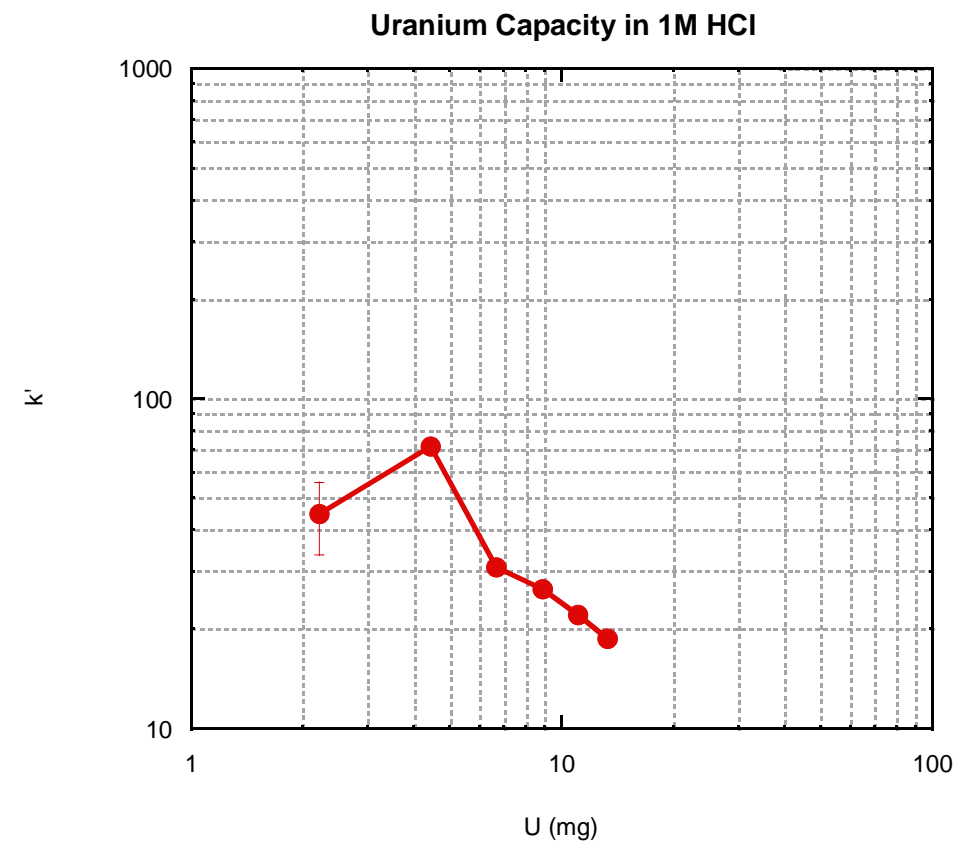

To determine the Uranium capacity on DGA resin in the nitric species, column elution curves of Uranium (VI) were analyzed in varying concentrations for breakthrough. The loading solutions used were $1 \mathrm{~mL}$ of $4.44 \mathrm{mg} \mathrm{U}(\mathrm{VI}) / \mathrm{mL}$ and $22.2 \mathrm{mg}$ $\mathrm{U}(\mathrm{VI}) / \mathrm{mL}$ at $0.1 \mathrm{M} \mathrm{HNO}_{3}$. As seen, in the elution profiles below there is no breakthrough in the elution curves. There is broadening and higher intensity of the $22.2 \mathrm{mg} / \mathrm{mL}$ loading solution, which is expected. However the shape of the elution peak remains symmetrical, proving that its capacity has not been exceeded. The theorized capacity for $0.3836 \mathrm{~g}$ DGA is at a loading solution of $51.15 \mathrm{mg} \mathrm{U}(\mathrm{VI}) / \mathrm{mL}$. In the future elutions will be carried out at $52 \mathrm{mg} \mathrm{U}(\mathrm{VI}) / \mathrm{mL}$ to see if there is any breakthrough. 

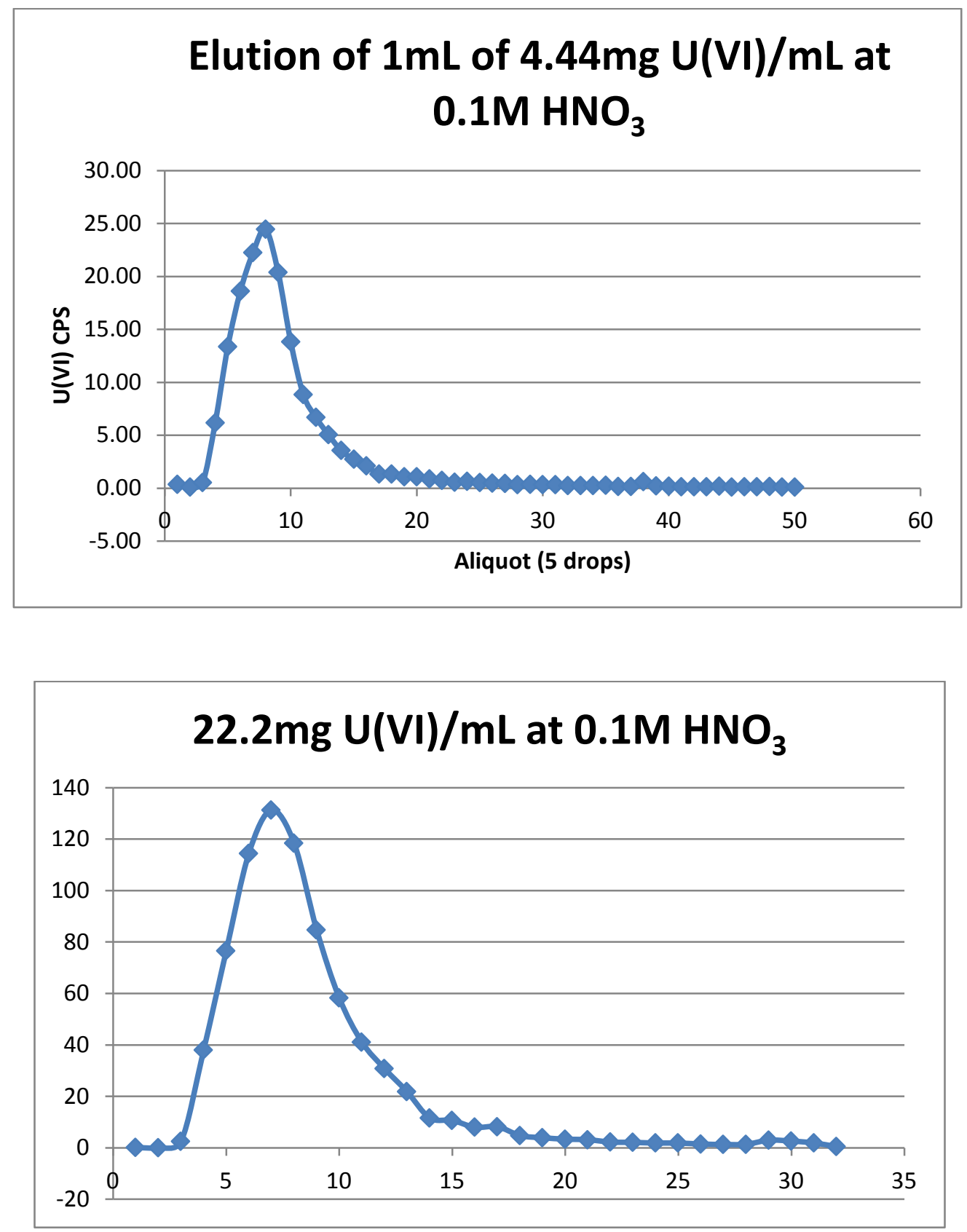


\section{REFERENCES}

1. Horwitz, E.P., Bloomquist, C.A.A., Orlandini, K.A., Henderson, D.J., Solvent Extraction Ion Exch., 23, 219 (2005)

2. Pourmand, A., Dauphaus, N., Talanta 81, 741-753 (2010)

3. Horwitz, E.P., McAlister, D. R., Thakkar, A. H., Solvent Extraction Ion Exch., 26, 12-24 (2008)

4. Guenther et al., PNL-5109-105, Pacific Northwest Laboratory, Richland, WA

5. Horwitz, E.P., McAlister, D. R., Solvent Extraction and Ion Exchange, 27:4, 474488, (2009) 